\title{
Pharmacodynamic Evaluation: Pain Methodologies
}

\author{
Pieter Siebenga, Pieter Okkerse, Guido van Amerongen, \\ Robert Jan Doll, Alex Mentink, Justin Hay, and \\ Geert Jan Groeneveld
}

\section{Contents}

General Introduction $\ldots \ldots \ldots \ldots \ldots \ldots \ldots \ldots \ldots \ldots \ldots \ldots \ldots \ldots \ldots \ldots \ldots \ldots \ldots \ldots \ldots \ldots \ldots \ldots, 2$

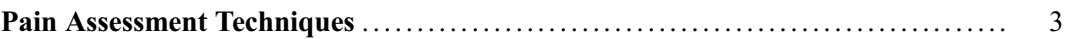

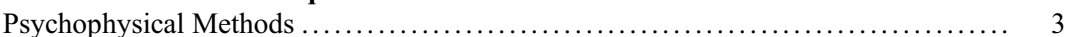

Electrophysiological and Imaging Methods .............................. 4

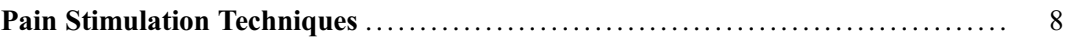

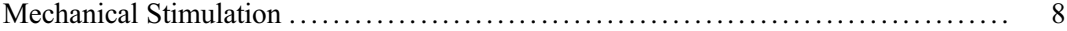

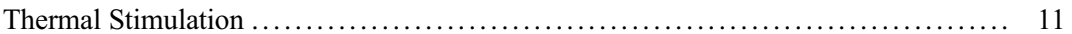

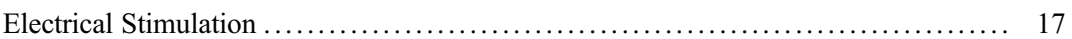

Chemical Stimulation ................................................... 20

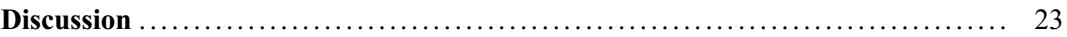

Healthy Subjects Versus Patients ....................................... 23

Predictive Value of Models for Drug Development ......................... 24

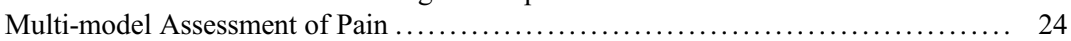

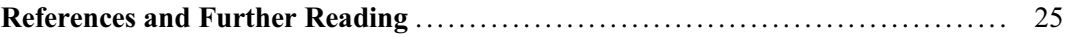

\begin{abstract}
Despite many advances in the last decades in understanding pain, the development of new analgesic compounds has not followed at the same pace. The development of more targeted analgesic compounds with fewer side effects is therefore essential. With an increased demand to demonstrate pharmacodynamic effects of
\end{abstract}

P. Siebenga $\cdot$ P. Okkerse $\cdot$ G. van Amerongen $\cdot$ R.J. Doll $\cdot$ A. Mentink · J. Hay · G.J. Groeneveld $(\bowtie)$

Centre for Human Drug Research, Leiden, The

Netherlands

e-mail: psiebenga@chdr.nl; pokkerse@chdr.nl; gvamerongen@chdr.nl; rjdoll@chdr.nl; amentink@chdr. nl; jhay@chdr.nl; ggroeneveld@chdr.nl new analgesic compounds, the importance of human evoked pain models is now higher than ever.

Pharmacodynamic evaluation with human evoked pain models offers the possibility to determine the dose ranges at which new analgesics exert their pharmacological effect. Pain models may also aid in the choice of target population, determine which modality of pain a new drug is expected to be most suitable, help to differentiate between a central or more peripheral mode of action of new drugs, and help determine which other effects contribute to its mode of action, e.g., sedation.

Human evoked pain models are conducted in standardized laboratories where factors like 
stimulus intensity, frequency, duration, and location can be controlled. Using pain models in healthy volunteers has important advantages over assessing the effects of new drugs in patients with pain; the pain elicited in human pain models is predictable in its intensity while clinical pain will naturally fluctuate. Analgesic properties can be investigated with pain models without the influence of accompanying symptoms that are often seen in patients with pain.

\section{General Introduction}

Pain is intended as a warning to the body that a noxious stimulus can (potentially) harm the body. The International Association for the Study of Pain (IASP) defines pain as an unpleasant sensory and emotional experience associated with actual or potential tissue damage or described in terms of such damage (Bonica 1979). Prevalence studies show that in Western countries $19-31 \%$ of the adult population suffers from a form of chronic pain (Macfarlane et al. 2013; Moore et al. 2015). Despite the availability of potent analgesics such as opioids, chronic pain remains a high unmet medical need as many effective analgesics have important side effects and chronic treatment with opioids leads to tolerance and addiction. The development of better and more specific analgesic compounds therefore remains essential. With an increased demand to demonstrate pharmacodynamic effects of new compounds as early as possible in clinical drug studies, the importance of human evoked pain models is now more than ever.

In a pure neurophysiological sense, nociceptive pain occurs when nociceptors are stimulated by noxious stimuli (e.g., mechanical, thermal, electrical, or chemical stimuli). After a threshold has been reached, the nociceptive nerve fiber transmits the pain signal to the spinal cord. The signal is modulated at several locations along ascending pathways through the dorsal horn and spinal cord. From the spinal cord, the pain signal is projected to supraspinal centers where the brain can modulate the excitatory activity via descending control (Olesen et al. 2012). Perception of pain is even more complex where more than one sensory system is responsible for transmission of the painful stimulus (Aguggia 2003).

From a more neuropsychosocial point of view, pain is a complex experience influenced by many factors such as emotion, fear, anxiety, but also cultural background, sex, genetics, and educational background. Due to its complexity, it can be difficult to assess the effects of analgesic drugs on pain in patients, and animal pain models demonstrate low predictability for clinical efficacy in humans. Several explanations are receptor dissimilarity between species, differences in pharmacokinetics, and morphological and functional differences between the brains of animals and humans (Olesen et al. 2012). Human evoked pain models can control some of these influencing factors. Therefore, these models are an important step in the translation of animal research to pain patients.

Pharmacodynamic evaluation through human evoked pain models offers the possibility to differentiate between a centrally or peripherally acting drug, for which modality of pain a new drug will be most suitable (nociceptive, neuropathic, or inflammatory), and which other effects contribute to its mode of action (e.g., sedation, tolerance) (Oertel and Lötsch 2013; Okkerse et al. 2017; Olesen et al. 2012; Staahl et al. 2009a). This can be done in early clinical trials with healthy volunteers, which is not only cost-reducing but also time saving. Other advantages of using human evoked pain models are (1) stimulus intensity, duration, and modality are controlled and do not vary over time; (2) differentiated responses to different standardized stimulus modalities; (3) the response can be assessed quantitatively and compared over time; (4) pain sensitivity can be compared quantitatively between various normal/ affected/treated regions; (5) models of pathological conditions can be studied and the effects of drugs on such mechanisms quantified; and (6) pain models can be easily performed in healthy subjects, who are easier to recruit into clinical studies (Arendt-Nielsen et al. 2007a).

Evoked pain is mostly short-lasting, with most stimuli being applied exogenously and are 
generally focused on cutaneous nociceptor activation. Arguably, evoked pain models are limited in intensity due to ethical constraints related to the risk of tissue damage. In contrast to natural occurring pain which is mostly caused by endogenous factors, longer lasting and influenced by complex emotions (Moore et al. 2013). Since clinical pain is a complex sensation involving psychological, physiological, and cognitive factors, no single pain model is able to replicate all aspects of clinical pain (Okkerse et al. 2017).

Several methods exist for evoking pain in humans, such as mechanical, thermal, electrical, and chemical stimulation. A stimulus can be either phasic or tonic. Stimuli can be applied to different tissue types for instance skin, muscles, or viscera (Arendt-Nielsen et al. 2007a). This chapter focuses on the different pain models that are used to induce evoked pain in humans and the means to assess the evoked pain. Human evoked pain models are divided into the energy domain (i. e., mechanical, thermal, electrical, and chemical induction) and are further subdivided into area of stimulation (i.e., skin, muscle, and viscera) that is stimulated.

\section{Pain Assessment Techniques}

An evoked pain model consists of two elements; a stimulus needs to be applied to evoke pain and the related pain response needs to be measured (Gracely 2013). Possible assessment techniques for evoked pain responses can be divided into several categories: psychophysical, electrophysiological, and imaging.

\section{Psychophysical Methods}

Psychophysical methods aim to describe the relationship between physical stimuli (section "Pain Stimulation Techniques") and corresponding subjective responses in a quantitative manner. These methods are widely used to study stimulus processing in various research fields, including pain processing. The methods to quantify the relationship between stimulus and response can be subdivided into unidimensional methods and multidimensional methods.

\section{Unidimensional Measures}

\section{Purpose and Rationale}

Unidimensional questionnaires such as the Numeric Rating Scale (NRS), the Verbal Rating Scale (VRS), or the Visual Analogue Scale (VAS) provide a single subjective measure to the intensity of a stimulus. More quantitative unidimensional measures are thresholds: the intensity where a stimulus is first perceived as painful (pain detection threshold), and the intensity where the stimulus is no longer tolerable (pain tolerance threshold).

\section{Procedure and Evaluation}

The NRS consists of a horizontal line with evenly spaced perpendicular lines. The patient or subject is asked to rate his or her pain from 0 to 10 (11 point scale) or from 0 to 100 (101 point scale) where 0 equals "no pain" and 10 or 100 equals "worst possible pain." The VRS consists of a list of descriptive terms to express the different levels of pain. It at least should include the extremes, in this case "no pain" and "worst possible pain." Additional terms usually used are "very mild pain," "mild pain," "moderate pain," "severe pain," and "very severe pain." The VAS is a horizontal line consisting of the two extremes and subjects are asked to indicate on the horizontal line indicating the perceived intensity.

For the determination of pain thresholds, the stimulus intensity increases until a certain pain threshold is reached (Gracely 2013). The pain detection threshold (PDT) is reached when a change in sensation from nonpainful to painful is felt by the subject. The pain tolerance threshold (PTT) is the stimulus intensity at which the pain is no longer tolerable. Depending on the method used, the stimulus is ceased before or when reaching the pain tolerance threshold.

Several stimulus modalities (such as thermal, mechanical, or electrical) can be used to quantify pain perception and to assess sensory function (Arendt-Nielsen and Yarnitsky 2009). These can then also be used as an indicator of the current 
state of the pain system. For example, it can be used to detect hyperalgesia, which is a condition in which an enhanced pain response to noxious stimuli is observed. Hyperalgesia is indicated by a decrease in the pain thresholds and an increase in pain to supra-threshold stimuli.

\section{Critical Assessment of the Method}

The main disadvantage of NRS, VRS, and VAS scales is that they measure a single qualitative aspect of pain, namely, intensity or unpleasantness, while pain consists of more qualities (section "Multidimensional Measures"). Moreover, even though these (subjective) unidimensional scales can be used as a coarse measure of the level of pain a subject experiences, they cannot be used to distinguish individual contributions of nociceptive and pain-related mechanisms.

\section{Modification of the Method}

To obtain a more detailed description of pain perception and qualities, multidimensional questionnaires can be used (section "Multidimensional Measures").

More advanced psychophysical procedures are being developed to relate stimulus properties (e. g., pulse width, number of pulses, and inter-pulse interval) and perceptions to nociceptive processes (Doll et al. 2016; Yang et al. 2015). Also, combining unidimensional measures with neurophysiological measures may provide more information on underlying processes.

\section{Multidimensional Measures}

\section{Purpose and Rationale}

Unidimensional questionnaires are often found to be limited in their capabilities in describing pain perceptions. Therefore, multidimensional measures provide means to describe perception using multiple sensory and affective qualities of pain.

\section{Procedure}

In contrast to the unidimensional measures, subjects are asked to fill in several answers to various questions, or have to choose from a large range of adjectives to describe their pain perception. One of the most widely used multidimensional tool is the McGill Pain Questionnaire (Melzack 1975). This questionnaire not only measures the pain intensity but also measures the sensory and affective qualities of pain. The McGill Pain Questionnaire has been used in a large number of studies and has been translated and validated in multiple languages (Melzack 2005; Melzack and Katz 2013).

\section{Critical Assessment of the Method}

Multidimensional questionnaires often take more time to complete than simpler unidimensional questionnaires. Particularly in a clinical setting, multidimensional questionnaires either need to be compressed (such as the short-form McGill Pain Questionnaire) or replaced by unidimensional questionnaires. Additionally, in the experimental setting of evoked pain models not all components of a questionnaire may be applicable, e.g., items related to affective aspects of pain sensation.

\section{Modification of the Method}

Numerous pain questionnaires exist that measure different qualities of neuropathic and non-neuropathic pain. These include the Pain Quality Assessment Scale (PQAS), Leeds Assessment of Neuropathic Symptoms and Signs (LANSS), and PainDETECT. Moreover, questionnaires targeting specific patients groups exist as well; the Western Ontario and McMaster Universities Osteoarthritis Index (WOMAC) and Knee Society Score (KSS) assign pain, stiffness, and functional scores to patients suffering from osteoarthritis.

\section{Electrophysiological and Imaging Methods}

Electrophysiological readouts include evoked potentials via electroencephalography (EEG). Imaging readouts include functional magnetic resonance imaging (fMRI) and positron emission tomography (PET). Electrophysiological and imaging readouts provide a more objective measurement of pain. However, they have a larger variation in outcome measurements, are more expensive, and are technically more difficult to 
perform in a large group of subjects (Arendt-Nielsen et al. 2007a; Kakigi et al. 2005; Wager et al. 2013).

\section{Functional Magnetic Resonance Imaging}

\section{Purpose and Rationale}

Neuroimaging has identified several cortical regions in the brain that are typically active when a painful stimulus is applied to the body. With fMRI these pain responses in the brain can be observed. Structures that are active during pain perception are the primary and secondary somatosensory, the cingulate, and the insular cortices which together are called the pain matrix (Ingvar 1999; Peyron et al. 2000; Porro 2003; Rainville 2002; Tracey and Mantyh 2007). Activation of the pain matrix due to nociceptive stimuli is the functional imaging analogue of conscious pain perception. Measuring the activities in the pain matrix during a painful stimulus can be used as an objective measure for pain perception (Borsook et al. 2010).

\section{Procedure and Evaluation}

A subject is given a painful stimulus while being scanned in the MRI. fMRI measures brain activity by detecting changes in blood flow (hemodynamic response) associated with neuronal activation (Huettel et al. 2014). It uses the relative abundance of deoxyhemoglobin in blood that changes the proton signal from water molecules surrounding a blood vessel, producing blood oxygenation level-dependent contrasts (BOLD) (Ogawa et al. 1990). Via the BOLD signal an indirect index of neural activity is provided. Several fMRI methods are used in pain research, which reveal the neural correlation of pain perception and modulation by characterizing the brain response to evoked stimuli (e.g., pain, allodynia), task-driven responses, or drugs (phMRI) (Borsook et al. 2010).

\section{Critical Assessment of the Method}

This noninvasive method of measuring pain can provide a measure of cerebral perfusion that correlates with an acute painful stimulus in healthy volunteers. Detecting chronic pain is more complex due to confounding factors like disease and treatment. Brain systems like emotion, memory, and motivation are also active during measurement in these patients (Borsook et al. 2010). These systems can also be triggered by placebo analgesia, which adds to the complexity (Morton et al. 2016). Additionally, the resolution of fMRI is inferior compared to the EEG, which means that it is not suitable to investigate the primary neuronal activity directly related to the pain stimulus and less suitable to investigate the deeper structures of the brain (e.g., brainstem and thalamus) (Olesen et al. 2012).

\section{Modifications of the Method}

When including fMRI in a study, a distinction can be made in the type of pain model that will be used during the study. Mechanical (Baron et al. 1999), thermal (Lapotka et al. 2017; Shukla et al. 2011), electrical (Kocyigit et al. 2012), and chemical (Baron et al. 1999) induced pain models can be used during an fMRI scan, with the exception of models that entail the use of water and metal. Modifications can be made in the type of MRI, protocol used for scanning, and analyzing protocols.

\section{Electroencephalography and Evoked Potentials}

\section{Purpose and Rationale}

EEG is a noninvasive technique which records (spontaneous) synchronized postsynaptic neuronal activity of the human cortex. In contrast to brain imaging techniques, EEG has a high temporal resolution. This high resolution makes EEG an effective method of observing (rapid) changes in brain activity. Additionally, EEG is a suitable method for recording evoked potentials (EP) to painful stimuli (e.g., thermal, mechanical, or electrical) and may provide important information on (central) pain processing (Mouraux and Iannetti 2008).

\section{Procedure and Evaluation}

To record EEG, several electrodes are placed on the scalp, either using individual $\mathrm{Ag} / \mathrm{AgCl}$ electrodes or specialized caps. The impedance should 
be similar among all electrodes and is advised to be held under $50 \mathrm{k} \Omega$. Quantifying resting state EEG can be done by means of spectral analysis. Due to its nonstationary behavior, recorded data is divided in short epochs ranging between $2 \mathrm{~s}$ and $10 \mathrm{~s}$ (Jobert et al. 2013). Each epoch is then transformed into the frequency domain and after removing or correcting epochs affected by artifacts (e.g., ocular or muscular activity) averaged. The frequency range is then subdivided into bands (i.e., delta, theta, alpha, beta, and gamma) and then integrated over frequency bands to obtain the total power per frequency band.

EPs are monophasic deflections of spontaneous EEG and are time and phase locked on the onset of the stimuli (Mouraux and Iannetti 2008). These waveforms are typically characterized by their polarity, latency, amplitude, and position on the scalp. As the signal-to-noise ratio (SNR) is relatively low when recording EPs, repeatedly stimulating and recording cortical responses is required. This allows improving the SNR by means of averaging and allows the characterization of the evoked response in terms of the amplitudes and latencies. The data collected generally includes the peaks and latencies of the N1, N2, P2, and P3, or the top-top amplitude between N2 and P2 (Treede et al. 2003). Moreover, the reaction time after the presentation can also be recorded. The N1 is most prominent at the contralateral temporal side (i.e., T3 or T4) referenced to the frontal Fz. The N2 and P2 are most prominently visible at the vertex $\mathrm{Cz}$ referenced to the (linked) earlobes A1 and A2. The P3, which is not thought to be nociceptive specific, has a relatively long latency and is best observed at Pz referenced to the earlobes.

\section{Critical Assessment of the Method}

It is important to know that EEG recordings will be contaminated with artifacts. Common sources of artifacts are ocular movements and blinks, muscle contraction, and cardiac activity. Each of these artifacts have their own characteristics in both time domain and frequency domain and must be dealt with prior to analyzing EEG. Possibilities for dealing with these artifacts are either excluding parts of the recording for analysis or correcting for them (e.g., by using regression techniques, filtering, or blind source separation techniques).

EPs have been shown to be sensitive to various changes in pain pathways. EPs are sensitive to changes induced by analgesics (Schaffler et al. 2017). It must be taken into account, however, that the amplitudes of the EPs are dependent on the attention of the subject; reduced attention results in significantly lower peak amplitudes. Moreover, the across trial variability is relatively high making comparisons between groups and trials complicating.

\section{Modification of the Method}

When several electrodes are recorded during a resting state EEG, multichannel topography allows observing the activity recorded at several locations. Time-dependent changes in power spectra can therefore also be visualized. Even though EEG has a relatively low spatial distribution in contrast to techniques such as fMRI, source localization techniques are used to find brain sources of the recorded potentials (Grech et al. 2008). However, high-density electrode placement is required for more reliable source localization (Song et al. 2015).

As a result of averaging EPs, non-phase-locked information is lost. Time-frequency analysis of epochs does provide the means to study nonphase-locked information (Hu et al. 2015; Mouraux and Iannetti 2008).

\section{Nociceptive Spinal Flexion Reflex}

\section{Purpose and Rationale}

The nociceptive spinal flexion reflex (NFR), also called the RIII reflex, is a physiological, polysynaptic reflex allowing for painful stimuli to activate an appropriate withdrawal response (Skljarevski and Ramadan 2002). It is one of the available tools for objective quantification of spinal nociception in humans. The NFR reflex can be elicited in all four limbs. Here, the most standard procedure, with stimulation of the lower limb (sural nerve), is described. 


\section{Procedure and Evaluation}

Electrical constant current stimulation is delivered to the retromalleolar pathway of the sural nerve. Each stimulus consists of five pulses of $1 \mathrm{~ms}$ duration, separated by $4 \mathrm{~ms}$, resulting in a total duration of $21 \mathrm{~ms}$. Electromyographic responses are recorded from the ipsilateral biceps femoris (short head) via surface electrodes placed $4-5 \mathrm{~cm}$ apart over the muscle belly. The RIII reflex is identified as a polyphasic muscle response appearing with an onset latency between $90 \mathrm{~ms}$ and $130 \mathrm{~ms}$ after stimulation (Willer 1977). Following stimulation of the sural nerve, three responses are sequentially recorded: the tactile reflex (also known as RII), the nociceptive flexion reflex (RIII), and an involuntary movement signal (Skljarevski and Ramadan 2002). For quantification of the RIII reflex response, the reflex area is obtained by integrating the rectified signal within a $50 \mathrm{~ms}$ analysis window starting between $90 \mathrm{~ms}$ and $120 \mathrm{~ms}$ after stimulation. Stimulus-response curves are recorded by increasing stimulation intensity in $0.5 \mathrm{~mA}$ steps starting from $0.5 \mathrm{~mA}$. Participants can rate the pain intensity of each stimulus using an NRS or VAS. The pain threshold is determined as the stimulus intensity that first evokes a painful sensation (defined as an NRS rating $\geq 1$ or VAS $>0$ ). The RIII threshold is defined as the stimulus intensity that first evokes a reflex response exceeding a raw area of $100 \mu \mathrm{V} \times \mathrm{ms}$ (Ruscheweyh et al. 2015).

\section{Critical Assessment of the Method}

Reduction of the NFR by a pharmaceutical compound does not necessarily imply reduction of ascending nociception, but may also indicate modulation of other components that play a role in the RIII reflex, such as deep dorsal horn interneurons (Schouenborg et al. 1995) or motor neurons (Ruscheweyh et al. 2015).

\section{Modifications of the Method}

NFR is affected by demographic factors. It is indicated that female subjects and children have lower NFR thresholds (Page and France 1997; Sandrini et al. 1989). Other factors affecting the outcome include cardiac cycle, baroreceptors, stimulation site, and even diurnal rhythm
(Skljarevski and Ramadan 2002). All should be addressed before the start of the trial.

\section{Conditioned Pain Modulation}

\section{Purpose and Rationale}

Conditioned pain modulation (CPM) (also known as descending noxious inhibitory control (DNIC) for animal studies or heterotopic noxious counterstimulation) is a paradigm that uses a conditioning stimulus to influence a test stimulus and can be used to assess the endogenous analgesic capacity of both healthy subjects and patients (Nir and Yarnitsky 2015). The assessment of CPM provides an indication of the balance between descending facilitation and inhibition. It is hypothesized that malfunction of pain modulation network may be the cause, rather than the effect, of chronic pain development (Yarnitsky et al. 2010).

The endogenous network is mediated via descending serotonergic, noradrenergic, and dopaminergic pathways, with the conditioning stimulus activating decreasing the activity of oncells in the rostral ventromedial medulla (RVM) (Hernández et al. 1994).

\section{Procedure and Evaluation}

CPM is assessed by using a conditioning stimulus which is generally a tonic nociceptive stimulus; however, nonpainful conditioning stimuli have also been reported (Bouhassira et al. 1998; Lautenbacher et al. 2002). Various methods can be used as the conditioning stimulus. The method most commonly used is the cold pressor test (Pud et al. 2009). However, other stimuli have also been reported including hot water, ischemic pain, heat, chemically induced pain, electrical induced pain, and physically induced muscle pain (Popescu et al. 2010).

Various methods are used as the test stimulus including nociceptive flexion reflex, electrical, heat, and pressure stimulation, among others. CPM is considered to be a systemic experience, and as such, heterotopic stimulation is used for the assessment of CPM. CPM is assessed by comparing the endpoint from the test stimulus before and after administration of the conditioning stimulus. 
The duration of effect from the conditioned stimuli may be assessed in parallel or soon after administration of the conditioning stimulation; however, the duration of effect is paradigmdependent with reports of CPM effects lasting $5 \mathrm{~min}, 30 \mathrm{~min}$, and up to $60 \mathrm{~min}$ after application of the conditioning stimulus (Fujii et al. 2006; Graven-Nielsen et al. 1998; Tuveson et al. 2006).

\section{Critical Assessment of the Method}

CPM paradigms are reported to have both reasonable to high intra- and inter-individual variability especially due to the endpoint being derived from subjective pain reports (Nir and Yarnitsky 2015). Furthermore, divergent terminology used in the literature for the same phenomena complicate comparisons. Factors affecting CPM are use of medication, psychological state of subjects (anxiety, depression, emotional status, and attention span), and even ethnic origin (Goubert et al. 2015).

\section{Modifications of the Method}

As highlighted above and as with other pain models, there are numerous ways to assess CPM including different methods for the conditioning and test stimulus including using different application area. Furthermore, the endpoints vary considerably between research groups, with some groups assessing change in the test stimuli endpoint before and after the conditioning stimuli while others reporting changes in the endpoint during administration of the conditioning stimulus (Doll et al. 2014).

\section{Pain Stimulation Techniques}

\section{Mechanical Stimulation}

Human evoked pain models date back to the late nineteenth century, in which mechanical pressure was used to induce pain (Hardy et al. 1940). Over time, mechanical stimulation techniques became more accurate and are used to stimulate the skin, muscle, or viscera. The skin is the most used organ, because of its practical implementation. However, muscles can also be targeted both endogenous (post-exercise or ischemic) or exogenous (saline injection). Balloon distention in the viscera can be used to investigate new analgesic compounds in healthy volunteers but also as a diagnostic tool in patients (e.g., gut disorders). Mechanical stimulation can be divided into touch/pinprick, pressure, or pinching methods. This chapter focuses on the different techniques related to mechanical stimulation on the skin, muscles, and viscera using touch/pinprick, pressure, or pinching methods.

\section{Mechanical Skin Stimulation}

\section{Touch and Pinprick}

\section{Purpose and Rationale}

Mechanical stimulation via touch can be done with a cotton swab or a brushstroke (light mechanical stimulation) or pinprick. Light mechanical stimulation will not induce pain, but can be used to assess allodynia (lowered activation threshold for a nonpainful stimuli) by other pain stimuli.

A common method of applying pinprick stimulation is the use of von Frey filaments. These filaments are used to quantify touch as well as the PDT and the PTT. In animal and patient experiments, it is mostly used to determine functional recovery of $A \delta-$ or $A \beta$-fibers. In human pain models, it is also used to determine hyperalgesia effects (e.g., in the capsaicin/UV-B model).

\section{Procedure and Evaluation}

Von Frey filaments are calibrated filaments, originally made of human or animal hair, and later with acrylic or synthetic fibers or optical glass fibers. The filaments bend at a certain designated force (Fruhstorfer et al. 2001). The applied force is dependent on the stiffness, which is in turn dependent on the diameter of each filament. During stimulation, the filament is placed perpendicular to the skin and pressed down with a constant increase in force until it bends for $1 \mathrm{~s}$. Subsequently, the filament is removed with a constant decrease in force and the subject is given some time to evaluate the stimulation. 


\section{Critical Assessment of the Method}

The von Frey test is characterized by its simplicity, thereby showing advantages in clinical settings for rough quantification of functional nerve regeneration. In addition, it can be used to classify responders in the evaluation of hyperalgesia.

Although the von Frey method is still commonly used to evaluate peripheral nerve function in patients, it has several disadvantages as a human pain model. Pinprick stimulation always coactivates non-nociceptive $A \beta$-fibers. This may contaminate the signal and influence the results affecting the specificity. Additionally, intra- and inter-observer variability of this method is high. The skill of the observer will have an important impact on the results. Furthermore, each filament is produced for one constant standardized level of pressure, which means that many filaments are needed to determine sensory or pain thresholds with a high precision. Environmental changes may affect the calibration of the filaments. Lastly, it is difficult to combine von Frey stimulation with quantification methods that require time-locked responses, such as evoked potentials or time-frequency analyses in EEG.

\section{Modifications of the Method}

Von Frey filaments are inherently limited for method modification, because each filament is calibrated for one designated force application. Depending on the calibrated force, the filaments activate mainly $\mathrm{A} \beta$-fibers $(0.5-128 \mathrm{mN})$ or $\mathrm{A} \delta$ fibers (128-512 mN) (Curatolo et al. 2000). Both conventional as electronic pinprick paradigms have been described (Möller et al. 1998). To eliminate the intra- and inter-observer variation one can consider electronic pinprick devices.

\section{Impactometers/Pinch Interdigital Web/Joint}

\section{Purpose and Rationale}

Pressure algometers are usually applied to the muscle or bone, but other sites including the interdigital web, skinflap, earlobe, or a finger or toe joint can be used as an area of investigation
(Brennum et al. 1989; Curatolo et al. 1997; Staahl et al. 2006). Handheld or computer controlled pressure algometers are clinically similar to palpation (Olesen et al. 2012). For methods using a pinch methodology, the pain is due to a combination of mechanical stimulation and local ischemia, while when pressure is applied to muscle the pain is related to muscle strain (Olesen et al. 2012).

\section{Procedure and Evaluation}

A pressure algometer is applied to the area of interest. In a controlled manner, the pressure increases at a constant rate until a psychophysical endpoint of interest is attained. Many commercial handheld pressure algometers provide user feedback to ensure pressure is applied at a constant rate. For repeated applications, the pressure algometer should be applied to the same area to ensure intra-individual variability is minimized as variation in location can lead to different thresholds. PDT and PTT are the usual primary outcome measures.

\section{Critical Assessment of the Method}

For handheld pressure algometers, control of the rate of onset, muscle contraction, and examiner expectations are the primary limitations (Woolf and Max 2001). Differences in the size and shape of the probe limit comparisons between research groups.

\section{Modifications of the Method}

The model can be used in combination with other methods that induce hyperalgesia or sensitization. Stimulus-response curves can be compared with nonsensitized locations.

Rather than using a punctate pressure algometer, cuff algometry can be used with the advantage that the model is generally computercontrolled thereby controlling the rate of application of the pressure pain (Polianskis et al. 2001). Pain induced by cuff algometry is primarily related to muscle pain with minimal contribution from skin nociceptors. 


\section{Mechanical Muscle Stimulation}

\section{Post-exercise Muscle Soreness}

\section{Purpose and Rationale}

Delayed onset muscle soreness (DOMS) is believed to be mediated by a combination of lactic acid, muscle spasm, connective tissue damage, muscle damage, inflammation, and endogenous substances (e.g., bradykinin and prostaglandines) (Nie et al. 2006). This pain model is thought to mimic clinical pain by inducing central sensitization while having no spontaneous pain at rest compared with exogenous induced pain models (Olesen et al. 2012). Central sensitization is an increase in general excitability of the dorsal horn neurons which can be caused by nerve injury (Laird and Bennett 1993). Secondary hyperalgesia is thought of as a transient state of central sensitization (Torebjörk et al. 1992).

\section{Procedure and Evaluation}

Subjects perform an eccentric exercise that they are unaccustomed to with insufficient rest periods. Peak allodynia/hyperalgesia occurs $24-48$ h postexercise. The affected muscles are assessed with a VAS to evaluate pain intensity and pressure algometry to evaluate allodynia/hyperalgesia.

\section{Critical Assessment of the Method}

The method is somewhat nonspecific, with an inflammatory component but these may be site specific (Staahl and Drewes 2004).

\section{Modifications of the Method}

The method can be modified by using various locations/muscle groups with development of hyperalgesia dependent on the size of the muscle (Svenson and Arendt-Nielsen 1995).

\section{Ischemic Tourniquet}

\section{Purpose and Rationale}

The tourniquet model is a tonic pain model with nociceptive contributions from the muscle, skin, and periosteum (the vascular connective tissue enveloping the bones). Clinically, tourniquets are used to perform intravenous regional anesthesia or to provide a bloodless operating field. The tourniquet leads to metabolic changes, primarily acidosis, and compression which leads to the release of prostaglandins. Neuropathic pain induced by nerve compression may also contribute to the pain felt (Kumar et al. 2016). The method can also be used as a conditioning stimuli for the CPM paradigm (section "Conditioned Pain Modulation").

The pain is thought to be mediated by the unmyelinated, slow conducting $\mathrm{C}$-fibers that are usually inhibited by the A $\delta$-fibers (Kumar et al. 2016). The A $\delta$-fibers are blocked by mechanical compression after about $30 \mathrm{~min}$, while the Cfibers continue to function (Casale et al. 1992). Tourniquet compression leads to release of prostaglandins by the injured cells (Kumar et al. 2016). These prostaglandins increase pain perception by sensitizing and exciting pain receptors. Also, limb ischemia causes central sensitization (Kumar et al. 2016).

\section{Procedure and Evaluation}

A pneumatic tourniquet is applied to an extremity, generally the thigh, following exsanguination of the leg. The cuff is inflated above the systolic blood pressure with ranges of $100-600 \mathrm{mmHg}$ above the systolic pressure having been reported (Smith et al. 1966).

\section{Critical Assessment of the Method}

For healthy subjects, the tourniquet can be left for up to $2 \mathrm{~h}$; however, pain is nonspecific with pain being felt under the tourniquet and/or in the lower limb. The method can also lead to temporary hypoesthesia and lower limb paralysis. Following reperfusion, the subject may experience hyperalgesia/allodynia and muscle cramps in the affected limb.

\section{Modifications of the Method}

The method can also be used with combination with voluntary muscle contractions or exsanguination of the leg by gravity or esmarch bandage (Hagenouw et al. 1986; Olesen et al. 2012). The width and type of tourniquet and the maximum inflation pressure can be used to modify the method. 


\section{Hypertonic Saline Injection}

\section{Purpose and Rationale}

Intramuscular injection of hypertonic sodium chloride (4-6\%) results in a tonic, deep, diffuse pain. The pain usually lasts for several minutes following infection and leads to both local and referred pain. The pain is primarily mediated via direct excitation of C-fibers than caused by salineinduced tissue injury (Schulte et al. 2006; Svendsen et al. 2005). The procedure can also be used to induce local, cutaneous hypoesthesia (Graven-Nielsen et al. 1997).

\section{Procedure and Evaluation}

A bolus saline solution is injected intramuscularly using computer-controlled infusion pump. Earlier models used manual bolus injections (GravenNielsen and Mense 2001). Pain intensity is measured by using a VAS with peak pain or area under the curve (AUC) being the primary outcome measures. Referred pain patterns and changes in the pressure pain thresholds of the local and referred pain areas can also be assessed (Ge et al. 2006).

\section{Critical Assessment of the Method}

A limitation of the model is that hypertonic injection may elicit excitation from both non-nociceptive and nociceptive nerve fibers (Korotkov et al. 2002).

\section{Modifications of the Method}

Potassium chloride is occasionally used instead of sodium chloride. Various sites can be used for injection with the most common being the musculus trapezius and the musculus tibialis anterior (Ge et al. 2006; Schulte et al. 2006).

\section{Mechanical Visceral Stimulation}

\section{Barostat/Esophagal Distention/Bladder Distention}

\section{Purpose and Rationale}

Induction of pain in viscera is difficult to perform due to the location of the organs associated with visceral pain as pain originates from the internal thoracic, pelvic, or abdominal organs (Johnson and Greenwood-van Meerveld 2016). Evoked pain models assessing mechanical visceral pain are generally limited to different accessible areas of the gastrointestinal (GI) tract, the urinary tract (Maggi 1990), and the uterine cervix (Drewes et al. 2003a).

\section{Procedure and Evaluation}

Mechanical stimulation of the viscera is generally performed using a balloon placed in the GI tract with the preferred locations being the esophagus or rectum. The most common method used is the barostat method whereby changes in air volume within a balloon while maintaining constant pressure are measured (Drewes et al. 2002). Generally, the balloon/bag is inflated until moderate pain is reported (up to approximately 7 on a VAS) and the corresponding balloon volume is reported (Staahl et al. 2006).

\section{Critical Assessment of the Method}

One of the main limitations of organ distention is the distortion of the balloon. However, calculation of strain by impedance planimetry or calculation of balloon radius may overcome these limitations (Drewes et al. 2003a; Staahl et al. 2006). Assessment of visceral pain is difficult due to the diffuse, referred, vague, and deep nature of the pain associated. Furthermore, autonomic reactions and the risk of perforation may limit the use of visceral pain models (Ness and Gebhart 1990).

\section{Modifications of the Method}

Perfusion of the GI tract with chemical substances (e.g., acid or capsaicin) can be used to sensitize the organs and nervous system and generally mimics the clinical situation where the organs are hypersensitive (Johnson and Greenwood-van Meerveld 2016).

\section{Thermal Stimulation}

Thermal stimuli can be used to induce pain. These can be roughly subdivided in cold and heat stimuli. Cold stimulation can be induced by emerging a body part in a cold water bath (cold pressor test), by using a cooling thermode, by inducing a 
freezing lesion, or by applying ice directly to the skin. Heat pain tasks are among the most widely used pain models in human volunteers to investigate nociception, due to the relative ease of application and robustness. Nociceptive nerve fibers are activated by changes in temperature detected by a range of thermal receptors, of which Transient Receptor Potential ion channel subfamily vanilloid (TRPV) is most responsible. When a sharp increase in temperature $\left(>43^{\circ}\right)$ is detected, $\mathrm{A} \delta$-fibers are activated, whereas $\mathrm{C}$-fibers are activated by slower or more dull temperature changes. Different clinical pain states can lead to sensitization to heat pain stimuli and consequently lower activation thresholds, which can be replicated using hyperalgesia models.

\section{Thermal Skin Stimulation}

\section{Cold Stimulation}

\section{Cold Pressor}

\section{Purpose and Rationale}

The cold pressor test can be used to investigate nociception, but also cardiovascular responses (sympathetic functions) and can be used as to induce CPM. The cold sensation and pain induced by this method is mediated by activity of A $\delta$ fibers (cold sensation) and C-fibers (cold pain) (Olesen et al. 2012).

\section{Procedure and Evaluation}

One of the methods of induction of cold pressor pain is based on methods previously described by Eckhardt et al. and Jones et al. (Eckhardt et al. 1998; Jones et al. 1988). Here, subjects place their nondominant hand into a warm water bath for $2 \mathrm{~min}$. At $1 \mathrm{~min} 45 \mathrm{~s}$, a blood pressure cuff on the upper-arm is inflated to $20 \mathrm{mmHg}$ below resting diastolic pressure. At $2 \mathrm{~min}$, the subject moves their hand from the warm water bath, directly placing their hand into a cold water bath. The baths are two thermostat-controlled, circulating water baths set at $35.0 \pm 0.5{ }^{\circ} \mathrm{C}$ and $1.0 \pm 0.5{ }^{\circ} \mathrm{C}$, respectively. The subject rates their pain intensity using a rating scale (e.g., VAS or NRS). When pain tolerance is reached, or when a time limit is reached, subjects are instructed to remove their arm from the water, at which point the blood pressure cuff is deflated. Typically, PTT expressed in seconds after immersion in the cold water is recorded as primary outcome measure.

\section{Critical Assessment of the Method}

Many different methodologies have been described which negatively influences the extent to which different studies can be compared. Small variations in water temperature can result in significant changes in pain intensity and tolerance times (Mitchell et al. 2004). Therefore, it is important to use water baths that are able to circulate that water to prevent warming of the water around the hand.

\section{Modification of the Method}

Different temperature settings of the water baths can be used and different body parts can be immersed in the baths. Instead of a cold water bath, also a cool gel substance has been reported to induce pain which makes it suitable for fMRI testing (Lapotka et al. 2017). Also a blood pressure cuff can be used to prevent compensatory blood flow to the hand.

\section{Cooling Thermode}

\section{Procedure and Evaluation}

The cold pressor test (section "Cold Pressor") is the most commonly used method to induce cold pain. However, a cooling thermode can also be used to induce cold pain. A contact thermode is attached to a part of the human body. The method consists of administering a temperature with an intensity that gradually decreases at a constant rate, usually $1{ }^{\circ} \mathrm{C}$ per second. The subject halts the stimulus when the cold pain threshold is reached or when a set lower cut off temperature is reached. Most studies using this methodology only report the cold pain detection threshold; the temperature at which the sensation has "just become painful." 


\section{Critical Assessment of the Method}

For none of these compounds this methodology provided evidence for analgesic efficacy, while other pain induction methods were able to provide this evidence (Staahl et al. 2009a, b). The added value of this methodology in clinical pharmacology studies is limited.

\section{Modification of the Method}

Several adjustments can be made to this paradigm. The temperature at which the test starts, the rate at which the temperature decreases, and the temperature at which the test ends can be modified. Cold hyperalgesia can be induced by applying menthol to the skin prior to testing (Andersen et al. 2015). A mean threshold of multiple measurements can be taken to minimize subject variability.

\section{Thermal Grill}

\section{Purpose and Rationale}

The thermal grill is based on the phenomenon in which simultaneous application of innocuous cutaneous warm and cold stimuli can induce a sensation of burning pain, the so-called "thermal grill illusion." The illusion is thought to be caused by the central integration of ascending pain and temperature sensory channels, where the inhibition that is usually exerted by the cold afferents on the nociceptive system is reduced (Bouhassira et al. 2005; Craig and Bushnell 1994).

\section{Procedure and Evaluation}

The thermal grill consists of a number of juxtaposed bars of cold and warm nonpainful temperatures (e.g., $18^{\circ} \mathrm{C}$ and $42^{\circ} \mathrm{C}$ ) on which the subject places a body part for a certain period of time. Possible outcome measures, during and after the test, can be cold and hot sensation, pain intensity, and sensation of unpleasantness.

\section{Critical Assessment of the Method}

Studies in which the thermal grill has been used applied a range of combinations of warm and cold stimuli to assess relationships between painful and nonpainful sensations (Adam et al. 2014; Kern et al. 2008; Okkerse et al. 2017). The occurrence of paradoxical pain elicited by the thermal grill illusion can be variable. A study by Bouhassira and colleagues reported a large subpopulation of subjects who only reported paradoxical pain when large cold-warm differentials were applied (Bouhassira et al. 2005). Due to the apparent necessity to tailor this method to each individual subject, it is difficult to standardize this method.

\section{Modification of the Method}

For the induction of the thermal grill illusion, different temperature combinations of the cold and warm bars can be used. Also a different number and width of the bars and a different distance between the bars can be used.

\section{Skin Freezing}

\section{Purpose and Rationale}

Skin freezing is an induction method of hyperalgesia. Hyperalgesia can be experimentally induced with chemical and electrical stimulation or by injuring tissue using UVB or freeze lesions (Kilo et al. 1994; Lötsch and Angst 2003).

\section{Procedure and Evaluation}

A copper cylinder is cooled to $-28^{\circ} \mathrm{C}$ and placed to a part of the skin for a brief period of time. For better thermal contact, a filter paper soaked with saline can be placed between the skin and the copper cylinder. This freezing induces cutaneous inflammation and hyperalgesia. Approximately $24 \mathrm{~h}$ after induction sensory testing can be performed.

After induction of the freeze lesion, pain and sensation testing can be performed via mechanical stimulation with stroking brushes (subjects have to indicate if a stroke with a certain load is painful), von Frey filaments (with increasing strength, subject have to indicate when the punctuation becomes painful) and blunt pressure using a pressure algometer (threshold in $\mathrm{N} / \mathrm{cm}^{2}$ ), or electrical stimulation using a constant current device (thresholds in $\mathrm{mA}$ ).

\section{Critical Assessment of the Method}

There are only a handful of studies reporting using freeze lesions. An advantage of this method is the 
extent to which this methodology can be standardized. The temperature, pressure, and exposure time for induction of the lesion can be controlled. Furthermore, the lesion provides stable test conditions 1 day after induction. The lesion ceases over a period of days (Lötsch and Angst 2003). The freeze lesion may cause hyperpigmentation, which can be visible for several months (Kilo et al. 1994).

\section{Modification of the Method}

The location, temperature, pressure, and exposure time for induction of the lesion can be varied. Furthermore, the time window between induction of the lesion and testing can be changed.

\section{Heat Stimulation}

\section{Heating Thermode}

\section{Purpose and Rationale}

Heat pain thresholds can be determined by applying a peltier element to the skin, where the increase in temperature activates nociceptors via TRPV and TRPM channels (Caterina et al. 1997; Li 2017).

\section{Procedure and Evaluation}

A contact heat thermode probe, typically with a surface of $9.0-12.5 \mathrm{~cm}^{2}$, is placed on the skin at a standardized nonpainful baseline temperature between $30{ }^{\circ} \mathrm{C}$ and $39^{\circ} \mathrm{C}$. Temperature is subsequently increased in a tonic or phasic fashion at a predetermined rate up to a temperature of $50-52{ }^{\circ} \mathrm{C}$. After a subject has indicated its pain detection or tolerance threshold, the probe is rapidly cooled to the baseline temperature. To reduce variability, the test can be repeated consecutively three times, and the average of these measurements is considered the pain threshold (Bishop et al. 2009). Outcome measures consist of pain thresholds as well as subjective pain scores (NRS, VAS).

\section{Critical Assessment of the Method}

Heat pain thresholds are considered to be robust and reproducible endpoints, due to their clear physiological relationship with nociceptor activation thresholds. This method is widely used and contact heat thermodes are commercially available. Limitations to using a contact heating thermode is the relatively slow heating and cooling rate of the thermode, and the fact that the thermode touches the skin compared to, for example, laser, making it less suitable for investigating temporal summation or specific activation

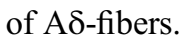

\section{Modifications of the Method}

In addition to investigating pain sensation in healthy skin, this method is often used to quantify sensitization, by comparing pain sensation of normal skin to an area of sensitized (UVB, capsaicin, menthol, cinnamaldehyde) skin (Roberts et al. 2011; Schaffler et al. 2017). The contact heat thermode can be used in conjunction with an EEG or fMRI modality, together known as CHEPS (Contact Heat Evoked Potentials). (Roberts et al. 2008, 2011).

\section{UVB Erythema}

\section{Purpose and Rationale}

Inflammation is the biological response to any type of bodily injury and is recognized by increased blood flow, elevated cellular metabolism, vasodilatation and the release of soluble mediators, and extravasation of fluids and cellular influx. Many different neuro-active factors are released during inflammation which stimulate nociceptors itself or by lowering the depolarization threshold of afferent nerves. The UVB (or "sunburn") model is regarded as a model for inflammatory pain and as such it is most sensitive to the effects of NSAIDs (Bishop et al. 2009; van Amerongen et al. 2016); in this model, hyperalgesia is evoked by exposing an area of skin to an individualized dose of UVB on the skin.

\section{Procedure and Evaluation}

Prior to the start of the study, the minimal erythema dose (MED) for a subject is determined (Sayre et al. 1981). Subsequently, a one-, two-, or threefold multiple of this dose is applied to the skin. Over the course of 2-96 h, a clearly discernible dose-related area of erythema becomes 
apparent, where allodynia and hyperalgesia is observed. Maximum hyperalgesia is reached at $24 \mathrm{~h}$ after irradiation. Typically, no background pain is observed. UVB induced hyperalgesia or allodynia can be quantified using a thermal (heat or cold) or mechanical (stroking, pinprick, pressure algometry) challenge. Pain thresholds or a subjective pain score can be used as endpoints. Mechanical allodynia to pinpricks or a pressure algometer can be expressed as a PDT, when ascending strengths of von Frey filaments are used. Moreover, the area of allodynia is measured using a fixed von Frey filament or brush.

\section{Critical Assessment of the Method}

The UVB model has been proven to be valuable tool to induce hyperalgesia and allodynia associated with inflammatory pain. One caveat, however, is the risk of postinflammatory hyperpigmentation (PIH) (Brenner et al. 2009). $\mathrm{PIH}$ is a harmless condition in which areas of skin become darker in color compared to the surrounding skin. PIH can occur at any age and any skin type; however, it is more common in patients with darker skin (Fitzpatrick skin type 4-6) (Fitzpatrick 1988).

\section{Modifications of the Method}

In general, there are three degrees of freedom to modify the UVB method: (1) the dose can be altered between estimated 1 to 3 MED (Bauer et al. 2015; Gustorff et al. 2004; Ing Lorenzini et al. 2012); (2) the location can be varied between leg, arm, and back; and (3) the time between UVB exposure and hyperalgesia assessment may vary between $12 \mathrm{~h}$ and $36 \mathrm{~h}$.

\section{Heat Burn Model}

\section{Purpose and Rationale}

A first-degree burn, comparable to a slight sunburn, resulting from a heat stimulus is used to initiate a local inflammatory response which results in reduced pain sensation thresholds (Thalhammer and LaMotte 1982). Additionally, the intense nociceptive excitation is thought to induce central sensitization (Pedersen and Kehlet 1998; Woolf 1983), rendering the burn model a model for both peripheral and central neuronal sensitization.

\section{Procedure and Evaluation}

A superficial cutaneous burn is induced using a thermode at a fixed temperature of $45-47^{\circ} \mathrm{C}$, for a period of 2-7 min, which is applied at a standardized pressure on the skin. The leg is predominantly selected as the location, but the arm is also used. The acceptable timeframe for detectable hyperalgesia and allodynia is typically up to $4 \mathrm{~h}$ after exposure to the heat stimulus. A distinction in sensitization can be made when investigating responses in the primary (exposed) area and the secondary (adjacent, nonexposed) area. Hyperalgesia resulting from the heat burn model is most distinctly quantified using a thermal or mechanical stimulus, due to locally reduced pain sensation thresholds in the primary area (van Amerongen et al. 2016). The PDT is predominantly selected as an outcome measure. Furthermore, the area of secondary hyperalgesia can be quantified using mechanical (pinprick, stroking) stimuli.

\section{Critical Assessment of the Method}

The heat burn model in combination with a mechanical (pinprick) assessment of sensitization is moderately sensitive to the effects of NMDA receptor antagonists (Ilkjaer et al. 1996; Mikkelsen et al. 1999). Analgesic effects of other treatments are less conclusive. As an evoked pain model, its principle is founded in controlled tissue damage, by inducing a first-degree burn, with reports of blistering in up to $20 \%$ of the studies conducted with this paradigm (van Amerongen et al. 2016). This may be considered to be an advantage in terms of external validity. However, from an ethical perspective a more short-lasting model without actual tissue damage may be preferred.

\section{Modifications of the Method}

The execution can vary from using a contact heat thermode with a short and intense stimulus $(100 \mathrm{~s}$ at $50{ }^{\circ} \mathrm{C}$ ), to the more commonly used prolonged exposure at lower temperature $\left(7 \mathrm{~min}\right.$ at $\left.47^{\circ} \mathrm{C}\right)$. Other heat sources, including laser stimulation or 
heat radiation, can be used. The arm or leg can be used as location of exposure.

Lasers

\section{Purpose and Rationale}

Laser stimulation (LS) uses the energy to heat up the epidermis and parts of the dermis with very brief (range of $\mathrm{ms}$ ) and powerful $\left(8-200 \mathrm{~mJ} / \mathrm{mm}^{2}\right.$ ) stimuli directed at the skin (Plaghki and Mouraux 2003). This type of stimulation causes a characteristic double pain sensation, consisting of an initial sharp pinpricking-like pain (A $\delta$-fibers) and a second longer burning pain (C-fibers) (Price 1996, 2000). Most commonly used laser stimulators are based on $\mathrm{CO}_{2}$, Argon, and the YAG (yttrium-aluminum-garnet).

\section{Procedure and Evaluation}

LS can stimulate the skin in a well-reproducible manner making it useful as a tool to elicit evoked potentials. Evoked potentials via EEG can easily be registered due to the brief nature of the stimulus of which the timing can be controlled as well. EEG has been used in combination with laser stimulation to distinguish between $\mathrm{A} \delta$ - and Cnociceptive activities (Mouraux et al. 2003).

\section{Critical Assessment of the Method}

Importantly, during LS no (A $\beta$-fibers) tactile mechanoreceptors are activated, making LS a useful tool for investigating the nociceptive system without the interference of non-nociceptive input. However, due to the fast rise in temperature of the skin, overstimulation may cause nociceptors to become fatigued over repetitive stimuli (Hüllemann et al. 2015). This in turn has an unwanted effect on quantification of the nociceptive system, as laser evoked potential habituation may occur (Hüllemann et al. 2015; Treede et al. 2003). It is therefore advised to vary the stimulation location slightly after each stimulus and use a randomized inter-stimulus interval. Additionally to habituation, precise settings are necessary to prevent damage to the skin. Hence, power, duration, and surface area must be properly set up.
Modifications of the Method

LS stimulates both A $\delta$ - and C-fibers by thermal activation. However, adjusting the stimulation method may shift the preferential activation of either nociceptor. Preferential C-fiber stimulation is based on a characteristic difference in heat

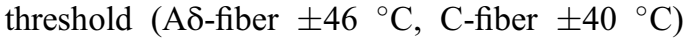
and distribution density in the upper skin (Ochoa and Mair 1969). Shifting between A $\delta$ and C-fiber activation using LS is possible by choosing the right pulse width, stimulation area in combination with keeping track of the skin temperature, and reaction time.

\section{Thermal Muscle Stimulation}

\section{Heated Saline}

\section{Purpose and Rationale}

Thermosensitive receptors located on muscle tissue afferents are thought to be involved in thermoregulation (Hertel et al. 1976). As such, these have been identified as potential targets to investigate nociception of deep muscle tissue. This is investigated by exposing muscular tissue to a high intensity thermal stimulation (Graven-Nielsen et al. 2002). Only a single study was found using this method.

\section{Procedure and Evaluation}

An intramuscular injection of sterile isotonic $(1.5 \mathrm{ml})$ heated saline is injected over $20 \mathrm{~s}$ $\left(270 \mathrm{ml} \mathrm{h} \_1\right)$ into the musculus tibialis anterior. Hyperalgesia can be quantified using a thermal and mechanical stimulus.

\section{Critical Assessment of the Method}

Compared to hypertonic saline in the same study, peak pain score resulting from intramuscular injection of isotonic saline at different temperatures was significantly lower. Mechanical sensitization appeared to be largest after injection at the highest temperature $\left(48{ }^{\circ} \mathrm{C}\right)$. To avoid cutaneous sensations, the injection site was anesthetized with intradermal injections of $0.2 \mathrm{ml}$ lidocaine before the intramuscular injection (Graven-Nielsen et al. 2002). 


\section{Modifications of the Method}

In the single study using this method, intramuscular injections of isotonic saline at different temperatures were investigated, ranging from $8{ }^{\circ} \mathrm{C}$ to $48^{\circ} \mathrm{C}$. Different muscles can be used for injection.

\section{Thermal Visceral Stimulation}

\section{Esophageal}

\section{Purpose and Rationale}

Thermal stimulation of the GI tract activates specific nociceptive afferents selectively through TRPV1. This is in contrast to mechanical and electrical stimulation, which activate afferents both superficial and deeper in the layers of the viscera (Sengupta and Gebhart 1994). This makes thermal stimulation of the GI tract a useful technique for specific activation of nonmyelinated afferents in the mucosa.

\section{Procedure and Evaluation}

In several studies, a model was used to thermally stimulate the esophagus (Arendt-Nielsen et al. 2009; Drewes et al. 2002, 2003b; Krarup et al. 2013). In these experiments, thermal stimuli were performed by changing the temperature $\left(5-60{ }^{\circ} \mathrm{C}\right)$ of recirculating water in a bag that was placed in the lower part of the esophagus. Temperatures were continuously measured inside the bag to control the thermal stimulation in the esophagus. Both for cold as for heat pain, a linear stimulusresponse $\left({ }^{\circ} \mathrm{C}\right.$-VAS $)$ can be observed.

\section{Critical Assessment of the Method}

The upper GI tract (esophagus) is able to differentiate between thermal stimuli in the temperature range that can be used without chronic damage. Quantification of the visceral pain is more difficult to distinguish.

\section{Modifications of the Method}

It has been demonstrated that fast increases in temperature $\left(1.5^{\circ} \mathrm{C} / \mathrm{min}\right)$ affect the precision of the response (Olesen et al. 2010). Therefore, the experimental esophageal model can be modified by using slower temperature increases to ascertain better results in pain assessments.

\section{Electrical Stimulation}

Electrical stimulation is used extensively for testing the sensitivity of the pain system in studies activating cutaneous structures, muscular structures, and in visceral structures (Andersen et al. 1994; Arendt-Nielsen et al. 1997; Laursen et al. 1997). Electrical stimulation initiates activity in nerve fibers directly without activating receptors. The stimulus intensity determines the size of the current field in the tissue and thereby the number of fibers activated (Andersen et al. 2001). In case a rectangular pulse is applied to the skin, thick fibers mediating mechanoreceptive input are activated at the lowest stimulus intensities. Increasing the stimulus intensity leads to concurrent activation of thin myelinated fibers (A $\delta$-fibers) and eventually C-fibers.

\section{Electrical Skin Stimulation}

Stimulation can be done cutaneous or intracutaneous with various stimulation paradigms with diverse waveforms, frequencies, and durations to selectively activate different afferents and nervous structures and thereby evoke various pain sensations. In addition, summated neural activity, as a result of the stimuli, can activate central mechanisms (Koppert et al. 2001), which is described further in paragraph "Electrical Single Stimulation."

\section{Electrical Single Stimulation}

\section{Purpose and Rationale}

This electrical stimulation paradigm leads to a nociceptive, A $\delta$ - and C-fiber mediated type of pain, which is well controllable. The electrical current stimulates nerve fibers directly because the intensity is far below that required to stimulate the actual receptors in the skin (Dotson 1997).

\section{Procedure and Evaluation}

For cutaneous electrical pain, two electrodes (Ag$\mathrm{AgCl})$ are placed on clean (scrubbed) skin, e.g., the skin overlying the tibial bone. Electrical resistance between electrodes should be less than $2 \mathrm{k} \Omega$. Each stimulus $(10 \mathrm{~Hz}$ tetanic pulse with a duration of $0.2 \mathrm{~ms}$ ) is controlled by a computer-controlled 
constant current stimulator. Current intensity increases from $0 \mathrm{~mA}$ in steps of $0.5 \mathrm{~mA} / \mathrm{s}$ (cutoff $50 \mathrm{~mA}$ ). The pain intensity after each stimulation is measured using an (electronic) VAS, until pain tolerance level is reached or a maximum of $50 \mathrm{~mA}$ is reached (Olofsen et al. 2005).

\section{Critical Assessment of the Method}

Electrical stimulation is easily controlled. Electrical stimulation of the skin to induce pain has several shortcomings: (1) they excite the afferent pathways in an unnatural synchronized manner; (2) they excite the full spectrum of peripheral nerve fibers (A $\beta-, A \delta$-, and $\mathrm{C}$-fibers); and (3) stimulation bypasses the receptors on the sensory nerve endings, and therefore, all information on specific activation and transduction processes is lost (Handwerker and Kobal 1993).

\section{Modifications of the Method}

$\mathrm{A} \delta$ - and C-fibers are activated at different stimulus intensities where $\mathrm{C}$-fibers have a higher activation threshold. Modeling approach can be useful for certain drug trials (Handwerker and Kobal 1993; Lee et al. 2007). The nonspecificity toward nociceptive specific stimulation is thought to be overcome by using small specialized needlelike electrodes. These electrodes slightly protrude through the epidermis and can preferentially stim-

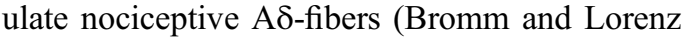
1984; Inui and Kakigi 2012; Mouraux et al. 2010). Intracutaneous stimulation can be chosen to mimic more a stinging/burning sensation and less throbbing (Bromm et al. 1984b).

\section{Electrical Burst (Temporal Summation)}

\section{Purpose and Rationale}

Increasing pain in response to a series of stimuli (temporal summation) reflects the first phase of "wind-up" in animal studies. Temporal summation can be induced with mechanical, thermal, and electrical stimulation (Arendt-Nielsen et al. 2000; Granot et al. 2006; Mauderli et al. 2003; Nie et al. 2006). Temporal and spatial summation evoked in the skin reflects a central nervous system modulation of the response, and it is believed to mimic neuropathic pain conditions because a likely contribution of central sensitization to neuropathic pain has been demonstrated (Woolf 2011). Application of transcutaneous electrical stimuli, with variation in electrical burst frequency, has been shown to be a reliable model to induce temporal summation in human subjects (ArendtNielsen et al. 2000).

\section{Procedure and Evaluation}

For burst stimulus, each single stimulus is repeated 5 times with a frequency of $2 \mathrm{~Hz}$. Pain threshold is taken as the value (mA) whereby a subject indicates either: all 5 stimuli are painful, or the train of 5 stimuli started feeling nonpainful but ends feeling painful (VAS $>0$ ) (Arendt-Nielsen et al. 2000; Hay et al. 2016).

\section{Critical Assessment of the Method}

As facilitated temporal summation is a feature in neuropathic pain patients, it has been hypothesized that induction of temporal summation using electrical stimulation can be used as a biomarker of drug effects on neuropathic pain (Arendt-Nielsen et al. 2007b). In a recent study, drug effects of analgesic compounds, including several used in the treatment of neuropathic pain, could not be established using this evoked pain paradigm, while other evoked pain paradigms manage to demonstrate pharmacological effects convincingly. This appeared to be related to a higher intra-subject variability that may necessitate larger subject groups (Okkerse et al. 2017).

\section{High-Frequency Electrical Stimulation}

\section{Purpose and Rationale}

High-frequency electrical stimulation (HFS) of the human skin induces increased pain sensitivity in the surrounding unconditioned skin (Van den Broeke et al. 2014). It has been shown that sustained nociceptive input can induce activitydependent changes in synaptic strength within nociceptive pathways, leading to an amplification of nociceptive signals (Ikeda et al. 2003). This is thought to play a key role in the development and maintenance of chronic pain and in particular some forms of hyperalgesia (Latremoliere and Woolf 2009; Sandkühler 2009). HFS-induced 
hyperalgesia within the surrounding unconditioned skin mimics the phenomenon of secondary hyperalgesia (Meyer and Treede 2004). As such, it constitutes a suitable model to study the mechanisms underlying central sensitization of nociceptive pathways (Klein et al. 2008).

\section{Procedure and Evaluation}

HFS is delivered to the test site, e.g., the volar forearm, and consists of 5 trains of $100 \mathrm{~Hz}$ pulses lasting $1 \mathrm{~s},(10 \mathrm{~s}$ interstimulus interval; $2 \mathrm{~ms}$ single pulse duration) at 10 times the detection threshold (Pfau et al. 2011). The electrical stimulation is generated by a constant-current electrical stimulator and delivered to the skin using a specifically designed electrode that has been demonstrated to activate peptidergic nociceptive afferents in the skin (Klein et al. 2004). The heterotopical effect of HFS is usually characterized using mechanical punctate stimuli. The test stimuli are applied to the skin surrounding the area onto which HFS is applied as well as to the same skin area on the contralateral arm, which serves as control to take into account a possible time-dependent habituation (van den Broeke et al. 2014).

The intensity of perception elicited by the three types of test stimuli is assessed using a numerical rating scale (NRS). After approximately $1 \mathrm{~h}$, the level of heterotopical hyperalgesia starts to diminish, however is still measurable and significant from baseline up to $8 \mathrm{~h}$ after HFS (Pfau et al. 2011).

\section{Critical Assessment of the Method}

HFS offers an alternative to other models that lead to secondary hyperalgesia, such as the capsaicin model or the UVB model with some important advantages. The major advantage versus the UVB model is that the mechanism underlying the secondary hyperalgesia is thought to involve heterosynaptic facilitation and, hence, to constitute a suitable model of central sensitization of nociceptive pathways (Klein et al. 2008), while the secondary hyperalgesia in the UVB model is thought to be due to a more peripheral sensitization of nociceptors, induced by inflammation (Bishop et al. 2009). The interval during which the secondary hyperalgesia is measurable can be carefully regulated and is relatively stable over the first hour after application of HFS (Pfau et al. 2011). The major disadvantage of this method is that is has not been used to demonstrate pharmacodynamic effects of analgesic drugs, although one recent study did show that the model can be combined with the assessment of drug effects (Vo et al. 2016).

\section{Modifications of the Method}

Modifications of the method are primarily related to the type of sensory stimulus to determine the heterotopical hyperalgesic effect and to the quantification. Heterotopical hyperalgesia can be demonstrated for mechanical punctate stimuli, but also for thermonociceptive stimuli induced by heat probes or laser stimulation. Van den Broeke et al. used the model in conjunction to event related potentials to objectively demonstrate the hyperalgesic phenomena (Van den Broeke et al. 2014).

\section{Electrical Muscle Stimulation}

\section{Purpose and Rationale}

Electrical stimulation of muscle tissue can be used to elicit both local and referred muscle pain. It possesses the ability to generate referred muscle pain in an "on and off" manner, and it is capable of maintaining referred pain for at least $10 \mathrm{~min}$ (Laursen et al. 1997). Intramuscular electrical stimulation appears to be used more often to study the nature of muscle pain than as a model to determine the pharmacodynamic effects of new analgesic compounds.

\section{Procedure and Evaluation}

In the intramuscular electrical stimulation paradigm, two needle electrodes with uninsulated tips are inserted into a muscle (e.g., the musculus tibialis anterior). A computer-controlled constant current stimulator is used to induce referred pain in the ventral part of the ankle by stimulating the muscle (Laursen et al. 1997). Each stimulation consists of five constant current rectangular pulses (1 ms) delivered at $200 \mathrm{~Hz}$. The referred pain threshold is defined as the lowest stimulus intensity required for the subject to notice a "just barely painful" sensation in the referred pain area. 
Referred pain thresholds are determined by a staircase regime consisting of five ascending and four descending series of stimuli (Gracely 1994; Laursen et al. 1997).

\section{Critical Assessment of the Method}

Electrical muscle and skin stimulation can use the same modalities which makes it possible to compare both models. A disadvantage of the model is that referred pain due to intramuscular electrical stimulation does not occur in all subjects; approximately, three quarters of patients experience it (Laursen et al. 1997). The referred pain typically arises approximately $40 \mathrm{~s}$ after the onset of electrical stimulation, which may mean that temporal summation is involved (Laursen et al. 1997).

\section{Modifications of the Method}

Modifications can be made with the stimulation settings. Pulse range of $100-200 \mathrm{~Hz}$ has been described, as well as a pulse width of 1-2 s (Laursen et al. 1997; van den Broeke et al. 2014).

\section{Electrical Visceral Stimulation}

In the viscera, it is difficult to determine the pain threshold to a single stimulus, whereas the pain threshold is easily determined if a train of stimuli is used. Furthermore, the referred pain area gradually expands if stimulation is continued for $120 \mathrm{~s}$ (Arendt-Nielsen et al. 1997).

\section{Chemical Stimulation}

Administration of algonenic substances to the skin, muscle, or viscera is believed to be a close resemblance of clinical inflammation. Various substances have been used to induce cutaneous hyperalgesia. The most commonly used are capsaicin, nerve growth factor (NGF), glutamate, mustard oil, and menthol, but other chemical stimulation models exist as well. Intramuscular injection of chemical substances is less common and harder to control in a clinical trial. The esophagus is the target organ when it comes to chemical viscera stimulation because of its easy access.

\section{Chemical Skin Stimulation}

\section{Capsaicin}

\section{Purpose and Rationale}

Capsaicin is a highly selective agonist for TRPV1, notorious for its pungent property in red chili peppers. TRPV1 channels are major transducers of physically and chemically evoked sensations (Hauck et al. 2015). The vanilloid 1 subtype is activated by noxious heat $\left(\geq 43^{\circ} \mathrm{C}\right.$ ) (Frølund and Frølund 1986) and is expressed on C-fibers, and on a subset of A $\delta$-fibers (Le Bars et al. 1979). The direct effects of applying topical capsaicin are burning sensations, hyperalgesia, allodynia, and erythema. In addition, it triggers the release of proinflammatory agents at peripheral terminals, such as substance $\mathrm{P}$ and calcitonin gene-related peptide (CGRP) (Kakigi 1994; Yarnitsky et al. 2010).

\section{Procedure and Evaluation}

Capsaicin can be administered topically and intradermal. Intradermal injection with capsaicin $0.1 \mathrm{mg}$ can cause hyperalgesia, but a dose of $100 \mathrm{mg}$ or higher is needed to produce hyperalgesia for an hour (Simone et al. 1987). A dose of $100 \mathrm{mg}$ is most frequently used (Baron et al. 1999; Serra et al. 1998; Torebjörk et al. 1992).

Topical administration of capsaicin in low concentrations (up to $3 \%$ ) can cause temporary mechanical and heat hyperalgesia. Sensitization can be induced by preheating the skin to $45{ }^{\circ} \mathrm{C}$ for 5 min with a thermode directly before capsaicin application. Sensitization can be rekindled throughout a study by reheating the skin up to $40{ }^{\circ} \mathrm{C}$ for $5 \mathrm{~min}$. Application of the capsaicin is most commonly done on the forearm or the back, but can be done on any area of the skin. Topical application of capsaicin can induce peripheral and central sensitization shown respectively by primary mechanical/thermal hyperalgesia and by secondary mechanical hyperalgesia/allodynia. This pain model can therefore be used to study novel analgesic compounds targeting these typical symptoms of neuropathic pain. Peripheral sensitization is caused by modulation of peripheral afferents and is therefore restricted to the site of 
injury, i.e., primary hyperalgesia. Central sensitization is caused by modulation of the nociceptive processing in the central nervous system. To quantify the effects of this pain model, laser stimulation (LS) can be used in combination with electro-encephalogram (EEG).

\section{Critical Assessment of the Method}

Peripheral sensitization is closely linked to primary hyperalgesia, and central sensitization is partly explained by hyperalgesia in the surrounding area, i.e., secondary hyperalgesia. Moreover, nociceptive integration at spinal cord level may include non-nociceptive mechanoreceptors. Therefore, central sensitization may also cause A $\beta$-fiber mediated pain (allodynia). Higher concentrations (capsaicin 8\%) initially causes increased sensitivity but is then followed by a decrease in sensitivity due to a reduced TRPV1 expression (Messeguer et al. 2006; van Amerongen et al. 2016). High concentration capsaicin is indicated in postherpetic neuralgia. Besides, capsaicin may also have a neurolytic property, where it (partly) eliminates epidermal nerve fibers (ENFs) in treated areas over time (Dworkin et al. 2010). Re-innervation occurs over time (Hüllemann et al. 2015).

\section{Modifications of the Method}

There are several variations that need to be addressed when designing a study utilizing capsaicin, e.g., concentration of the capsaicin, dose administration (intradermal or topical), vehicle of the capsaicin (alcohol or cream), duration of the application, location of administration, and pre-/ rekindling.

\section{Nerve Growth Factor Injection}

\section{Purpose and Rationale}

NGF is a member of the neurotrophin family, which also includes brain derived neurotrophic factor (BDNF), neurotrophin-3 (NT3) and neurotrophin-4/5 (NT4/5). NGF binds to both a high affinity tyrosine kinase receptor trkA and a low affinity receptor p75. NGF can sensitize nociceptors so that they show an increased response to thermal and chemical stimuli (Bennett
2007). Administration of NGF to human skin evokes mechanical sensitization and profound hyperalgesia to thermal stimuli that develops within $3 \mathrm{~h}$ postinjection and peaks between day 1 and 7 (Dyck et al. 1997). Sensitization to heat and hyperalgesia to cold develops within days after injection and lasts up to 21 days, while hypersensitivity to mechanical impact stimuli develops over a longer period and persists for at least 49 days (Rukwied et al. 2010). Intradermal NGF administration provokes a pattern of sensitization that can be used as experimental model for neuropathic pain (Rukwied et al. 2010).

\section{Procedure and Evaluation}

One microgram of human recombinant lyophilized NGF is dissolved in $50 \mu \mathrm{L}$ saline and injected intradermally into the central volar forearm. The same volume of saline is administered into the contra-lateral site as vehicle control (Rukwied et al. 2010). Vasodilatation upon NGF- and saline-injection can be recorded by laser Doppler imaging. Nociceptor sensitization can be explored to mechanical (touch, pinprick, pressure), thermal (cold, heat), and electrical (current pulses) stimuli. Stimuli for investigating static and dynamic allodynia and pinprick hyperalgesia are administered 5-7 cm distal from the injection site and continued in steps of $1 \mathrm{~cm}$ until the subject reports a definite increase of pinprick pain or switch from touch to an aversive sensation (Rukwied et al. 2010). The point where this starts is marked on the skin and the distance to the injection site measured. Pain thresholds and subjective scores with NRS/VAS can be used to evaluate the mechanical, thermal, or electrical stimulation.

\section{Critical Assessment of the Method}

Increased levels of NGF have been reported in human painful disorders including arthritis (Kidd and Urban 2001). Injection of NGF therefore appears to mimic processes found in clinical disease (Olesen et al. 2012). Even though NGF may also be upregulated in the UVB burn (Bishop et al. 2007), anti-NGF has been shown to only partially reduce UVB induced hyperalgesia (Bishop et al. 2007). Apparently, the NGF induced mechanism 
of mechanical sensitization is different to UVB evoked primary hyperalgesia. NGF induces a particularly long lasting mechanical sensitization including static allodynia and cold hyperalgesia without any visible signs of inflammation and therefore adds to the spectrum of human evoked pain models (Rukwied et al. 2010). The longlasting local allodynia and hyperalgesia after subcutaneous or intradermal injection, up to 49 days after injection, form the most important disadvantage of the model. Even though considered a model for neuropathic pain, it is unlikely that central sensitization plays a role.

\section{Modifications of the Method}

Systemic administration of NGF $1 \mu \mathrm{g} / \mathrm{kg}$ i.v. has been shown to lead to mild to moderate muscle pain mainly in the bulbar and truncal musculature that lasted 2-8 days (Petty et al. 1994).

NGF has been injected into the musculus masseter to induce allodynia and hyperalgesia and as a model of myofascial temporomandibular disorder pain (Svensson et al. 2003).

\section{Other Chemical Mediated Models}

\section{Mustard Oil}

Mustard oil is a plant-derived irritant. The noxious effects of mustard oil are currently ascribed to specific activation of the cation channel transient receptor potential, subfamily $A$, member 1 (TRPA1) in nociceptive neurons (Olesen et al. 2012). Topical administration leads to a burning pain in the area exposed to mustard oil as well as secondary allodynia and hyperalgesia in the surrounding unaffected area, similar to the topical capsaicin model (Koltzenburg et al. 1992).

\section{Menthol}

Menthol acts as an agonist on the transient receptor potential cation channel subfamily $\mathrm{M}$ member 8 (TRPM8) receptor. The topical application of high concentration (40\%) menthol is thought to activate and sensitize cold-sensitive TRPM8expressing C-nociceptors and activates cold-spe-

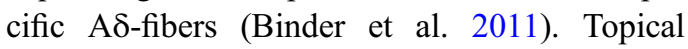

application has been used as an evoked pain model of cold hyperalgesia, which is a clinical symptom that occurs frequently in patients with peripheral or central nervous system lesions (Hatem et al. 2006). In addition to cold hyperalgesia, the model elicits primary and secondary mechanical (pinprick) hyperalgesia combined with the sensation of burning (Binder et al. 2011). The menthol model has been shown to be sensitive to a range of analgesics (Altis et al. 2009).

\section{Chemical Muscle Stimulation}

\section{Nerve Growth Factor}

Intramuscular injection with NGF is most commonly done in the musculus tibialis anterior or musculus masseter (Andersen et al. 2008; Svensson et al. 2008). It induced a long-lasting hyperalgesia and lower pressure pain threshold can be observed, lasting up to 4 days in the musculus tibialis anterior and up to 14 days in the musculus masseter (Andersen et al. 2008; Svensson et al. 2008). An advantage of the intramuscular NGF paradigm is the long-lasting hyperalgesia which can simulate clinical pain more than most other paradigms, but this is also the disadvantage where ethical consideration may play a role. The paradigm is difficult to control where hyperalgesia is dependent on the dose and the size of the muscle (Andersen et al. 2008).

\section{Chemical Visceral Stimulation}

\section{Esophagal (Gut) Perfusion with Acid, Alcohol, Glycerol, Capsaicin, and Hypertonic Saline}

\section{Purpose and Rationale}

Chemical stimulation of the GI tract may be used to stimulate C-fibers selectively via TRPV1 receptors and modulate the visceral pain system due to their sensitization effects. Having a model of central sensitization of the viscera can be helpful in the development of new analgesics, as this is 
thought to be an important element of chronic visceral pain.

\section{Procedure and Evaluation}

Using acid to stimulate the esophagus is the most used method to sensitize the gut (Bernstein and Baker 1958; Demedts and Tack 1998; Drewes et al. 2005; Reddy et al. 2005). However, other chemicals such as alcohol, glycerol, capsaicin, and hypertonic saline are used to stimulate the gut as well (Louvel et al. 1996; Drewes et al. 2003a, b). The chemical compound is usually infused into a container/bag residing in the esophagus with a small perfusion hole to release the compound into the esophagus. Chemical stimulation is able to modulate the visceral pain system by selectively activating nonmyelinated $\mathrm{C}$-fibers for a longer amount of time. This tonic activation may result in central sensitization effects, which can be quantified by subsequent thermal, electrical, or mechanical stimulation.

\section{Critical Assessment of the Method}

A high variation in the outcome measures is seen with this model. The reproducibility is challenging because several factors are hard to control, like exposure time to the chemical stimulus, size of the treated area, and latency time to onset of effects. Furthermore, tissue injury results in the release of multiple molecules working together, and to mimic this situation it may be necessary to use a mixture of chemical substances (Reddy et al. 2005). Blinding this procedure is difficult, since subjects are able to taste the compound. Therefore, the experimental setup requires that both subject and assessor are ignorant of the possible influence of the compound on the pain threshold (Drewes et al. 2003b).

\section{Modifications of the Method}

Each chemical substance will have an impact on the results. For example, the motility may interfere with the results when glycerol is used. Other stimuli, such as injection of hypertonic saline and application of capsaicin, the pain is elicited shortly after the chemical comes into contact with the mucosa, and the motility has minor impact on the results.

\section{Discussion}

\section{Healthy Subjects Versus Patients}

Despite many advances in the last decades in understanding pain, the development of new analgesic compounds lacked behind. In almost 60 years, only 59 compounds were registered for the treatment of pain, of which two thirds were specifically developed as analgesics (Kissin 2010). Historically, pain states have been classified and investigated on the basis of a disease state. Based on preclinical animal models, target patient populations were selected. In patient studies, efficacy is then reported as change in the patient's response to pain (McQuay and Moore 2013). Unfortunately, several promising compounds have failed in this late-stage development where pharmacotherapy only provides meaningful pain relief in less than $50 \%$ of patients with neuropathic pain (Finnerup et al. 2010, 2015). But a negative outcome does not automatically mean inefficacy of the compound. Pathophysiological mechanisms of pain vary between individuals with the disease state. Selecting and clustering the patients in groups of pathophysiology rather than disease might be necessary to obtain meaningful results. The use of human evoked pain models can provide more information.

Multimodal testing in healthy volunteers can provide information about the analgesic activity of the compound and possibly find the active dose level range. In a way, by using different pain modalities, the results will create a certain pain profile of the compounds (Okkerse et al. 2017). These results may reflect effects of analgesic drugs on mechanisms involved in clinical pain. Thus, multimodal pain testing may aid in determining the optimal target population for new analgesic compounds based on their profile of effects on a diversity of pain mechanisms and depending on the contribution of each of these mechanisms in clinical pain phenotypes. In several chronic pain populations, such as chronic whiplash, rheumatoid arthritis, vulvodynia, and fibromyalgia, changes in pain tolerance levels, pain modulation, and augmented brain responses and altered responses to analgesics have been found (Daenen 
et al. 2014; Hampson et al. 2013; van Laarhoven et al. 2013). Using evoked pain in these patients can provide insight into the analgesic mechanisms - or lack thereof - in these altered pain states (Olesen et al. 2012). In patients with chronic (neuropathic) pain, different sensory profiles exist. These profiles possibly match with different neurobiological mechanism of pain (Baron et al. 2017).

\section{Predictive Value of Models for Drug Development}

Human evoked pain models in healthy volunteers can be conducted in standardized laboratories. Factors like stimulus intensity, frequency, duration, and location can be controlled, and when a model is stable and reproducible, it can be regarded as suitable for pharmacodynamic evaluation of new analgesic drugs. Using pain models in healthy volunteers has important advantages over assessing the effects of new drugs in patients with pain; the pain elicited in human pain models is predictable in its intensity while clinical pain will naturally fluctuate, and in pain models analgesic properties can be investigated without the influence of accompanying symptoms that are often seen in patients with pain. However, it should always be asked whether a pain model at all resembles naturally occurring pain. Clinical pain is a subjective perception, influenced by cognitive processes, by emotions, social context, and even cultural background, while pain models are solely based on the infliction of a noxious stimulus and its response. An important question is whether or not a positive result in a certain evoked model is also predictive of clinical efficacy.

Two approaches have been used to investigate this. Moore and colleagues investigated which naturally occurring pain was physiologically most in agreement with evoking a pain response causing the same type of pain. For instance, they concluded that intramuscular electrical stimulation closely matched clinical acute musculoskeletal pain (Moore et al. 2013). Oertel and Lötsch evaluated the differences between human pain models and clinical efficacy. First they looked at which drugs were effective in different pain conditions (e.g., NSAIDs were effective for inflammatory arthritis), then they investigated which drugs were effective in which pain model (e.g., NSAIDs influence pain response in laser evoked pain). If a certain drug was effective both in the model and in the particular clinical setting, the model was concluded to possibly be predictive for the type of clinical pain. Some level of agreement could be observed for a large number of pain models with many different clinical forms of pain (Oertel and Lötsch 2013). In another review, the mutual agreement between pain models and clinical efficacy was statistically assessed. It was observed that a small set of pain models seemed predictive for efficacy in the clinic, for example, capsaicin induced hyperalgesia with mechanical stimulation is associated with trigeminal neuralgia and renal colic, and UVB induced hyperalgesia in combination with heat stimulation can be linked to burn injuries or postoperative pain (Lötsch et al. 2014).

Several reviews investigated which evoked pain models were sensitive to the analgesic effects of different classes of analgesics in healthy subjects (Oertel and Lötsch 2013; Okkerse et al. 2017; Staahl et al. 2009a, b). With the aid of these studies, well-considered decisions can be made on which evoked pain models to include in studies investigating potentially analgesic compounds.

\section{Multi-model Assessment of Pain}

Pain comes in various types and can originate in many different tissues. It is obvious that different analgesics will influence different types of pain according to their respective mechanism of action. If an analgesic drug with a novel mechanism of action is studied, it can occur that a single pain model, thought to relate to a specific clinical pain syndrome, demonstrates lack of efficacy of the new compound. In these cases, a combination of human evoked pain models can be used to screen for possible analgesic effects of these compounds. For instance, a combination of a mechanical, thermal, and electrical pain models: pressure 
stimulation assesses the nociception generated from within the muscle (Polianskis et al. 2001); cold pain induced by the cold pressor test mainly activates C-fibers in the skin (Olesen et al. 2012); heat stimulation initially activates A $\delta$-fibers in the skin, followed by $\mathrm{C}$-fiber activation; induction of inflammation via sunburn or UVB induces the production of cytokines that lead to sensitization of cutaneous nociceptors (Bishop et al. 2009); and electrical stimulation directly stimulates sensory nerve endings of both A $\delta$ and C-fibers in the skin (Handwerker and Kobal 1993). This multimodal testing with a battery of different pain models has been performed by multiple study groups (Enggaard et al. 2001; Okkerse et al. 2017; Olesen et al. 2014; Staahl et al. 2006). The batteries have in common that they induce pain via different modalities and in different tissues and mimics clinical pain better than a single pain model can. The multimodal batteries can be used to profile the analgesic effects of new drugs, to obtain the optimal dose of new analgesics, and to benchmark new drugs against profiles of well-known analgesics (Okkerse et al. 2017).

\section{References and Further Reading}

Adam F, Alfonsi P, Kern D, Bouhassira D (2014) Relationships between the paradoxical painful and nonpainful sensations induced by a thermal grill. Pain 155:2612-2617

Aguggia M (2003) Neurophysiology of pain. Neurol Sci 24:57-60

Altis K, Schmidtko A, Angioni C, Kuczka K et al (2009) Analgesic efficacy of tramadol, pregabalin and ibuprofen in menthol-evoked cold hyperalgesia. Pain 147:116-121

van Amerongen G, de Boer MW, Groeneveld GJ, Hay JL (2016) A literature review on the pharmacological sensitivity of human evoked hyperalgesia pain models. $\mathrm{Br}$ J Clin Pharmacol 82:903-922

Andersen OK, Jensen LM, Brennum J, Arendt-Nielsen L (1994) Evidence for central summation of C and A delta nociceptive activity in man. Pain 59:273-280

Andersen OK, Sonnenborg FA, Arendt-Nielsen L (2001) Reflex receptive fields for human withdrawal reflexes elicited by non-painful and painful electrical stimulation of the foot sole. Clin Neurophysiol 112:641-649

Andersen H, Arendt-Nielsen L, Svensson P, DanneskioldSamsøe B et al (2008) Spatial and temporal aspects of muscle hyperalgesia induced by nerve growth factor in humans. Exp Brain Res 191:371-382
Andersen HH, Poulsen JN, Uchida Y, Nikbakht A et al (2015) Cold and L-menthol-induced sensitization in healthy volunteers - a cold hypersensitivity analogue to the heat/capsaicin model. Pain 156:880-889

Arendt-Nielsen L, Yarnitsky D (2009) Experimental and clinical applications of quantitative sensory testing applied to skin, muscles and viscera. J Pain 10:556-572

Arendt-Nielsen L, Drewes AM, Hansen JB, Tage-Jensen U (1997) Gut pain reactions in man: an experimental investigation using short and long duration transmucosal electrical stimulation. Pain 69:255-262

Arendt-Nielsen L, Sonnenborg FA, Andersen OK (2000) Facilitation of the withdrawal reflex by repeated transcutaneous electrical stimulation: an experimental study on central integration in humans. Eur J Appl Physiol 81:165-173

Arendt-Nielsen L, Curatolo M, Drewes A (2007a) Human experimental pain models in drug development: translational pain research. Curr Opin Investig Drugs $8: 41-53$

Arendt-Nielsen L, Frøkjaer JB, Staahl C, Graven-Nielsen $\mathrm{T}$ et al (2007b) Effects of gabapentin on experimental somatic pain and temporal summation. Reg Anesth Pain Med 32:382-388

Arendt-Nielsen L, Olesen AE, Staahl C, Menzaghi F et al (2009) Analgesic efficacy of peripheral K-opioid receptor agonist CR665 compared to oxycodone in a multimodal, multi-tissue experimental human pain model. Anesthesiology 111:616-624

Baron R, Baron Y, Disbrow E, Roberts TP (1999) Brain processing of capsaicin induced secondary hyperalgesia: a functional MRI study. Neurology 53:548-557

Baron R, Maier C, Attal N, Binder A et al (2017) Peripheral neuropathic pain: a mechanism-related organizing principle based on sensory profiles. Pain 158:261-272

Bauer M, Schwameis R, Scherzer T, Lang-Zwosta I et al (2015) A double-blind, randomized clinical study to determine the efficacy of benzocaine $10 \%$ on histamine-induced pruritus and UVB-light induced slight sunburn pain. J Dermatolog Treat 26:367-372

Bennett D (2007) Sensitization of nociceptors. In: Schmidt RF, Willis WD (eds) Encyclopedia of pain, 1st edn. Springer-Verlag, Berlin/Heidelberg, pp 1338-1342

Bernstein LM, Baker LA (1958) A clinical test for esophagitis. Gastroenterology 34:60-81

Binder A, Stengel M, Klebe O, Wasner G et al (2011) Topical high-concentration (40\%) menthol-somatosensory profile of a human surrogate pain model. J Pain 12:764-773

Bishop T, Hewson DW, Yip PK, Fahey MS et al (2007) Characterisation of ultraviolet-B-induced inflammation as a model of hyperalgesia in the rat. Pain 131:70-82

Bishop T, Ballard A, Holmes H, Young AR et al (2009) Ultraviolet-B induced inflammation of human skin: characterisation and comparison with traditional models of hyperalgesia. Eur J Pain 13:524-532

Bonica JJ (1979) The need of a taxonomy. Pain 6:247-252 
Borsook D, Sava S, Becerra L (2010) The pain imaging revolution: advancing pain into the 21 st century. Neuroscientist 16:171-185

Bouhassira D, Sabaté JM, Coffin B, Le Bars D et al (1998) Effects of rectal distensions on nociceptive flexion reflexes in humans. Am J Phys 275:410-417

Bouhassira D, Kern D, Rouaud J, Pelle-Lancien E et al (2005) Investigation of the paradoxical painful sensation ('illusion of pain') produced by a thermal grill. Pain 114:160-167

Brenner M, Coelho SG, Beer JZ, Miller SA et al (2009) Long-lasting molecular changes in human skin after repetitive in situ UV irradiation. J Invest Dermatol 129:1002-1011

Brennum J, Kjeldsen M, Jensen K, Jensen TS (1989) Measurements of human pressure-pain thresholds on fingers and toes. Pain 38:211-217

van den Broeke EN, Geene N, van Rijn CM, Wilder-Smith $\mathrm{OH}$ et al (2014) Negative expectations facilitate mechanical hyperalgesia after high-frequency electrical stimulation of human skin. Eur J Pain 18:86-91

Bromm B, Lorenz J (1984) Neurophysiological evaluation of pain. Electroencephalogr Clin Neurophysiol 107:227-253

Bromm B, Jahnke MT, Treede RD (1984) Responses of human cutaneous afferents to $\mathrm{CO} 2$ laser stimuli causing pain. Exp Brain Res 55:158-166

Burke D, Mackenzie RA, Skuse NF, Lethlean AK (1975) Cutaneous afferent activity in median and radial nerve fascicles: a microelectrode study. J Neurol Neurosurg Psychiatry 38:855-864

Casale R, Glynn C, Buonocore M (1992) The role of ischaemia in the analgesia which follows Bier's block technique. Pain 50:169-175

Caterina MJ, Schumacher MA, Tominaga M, Rosen TA et al (1997) The capsaicin receptor: a heat-activated ion channel in the pain pathway. Nature 389:816-824

Craig AD, Bushnell MC (1994) The thermal grill illusion: unmasking the burn of cold pain. Science 265:252-255

Curatolo M, Petersen-Felix S, Arendt-Nielsen L, Zbinden AM (1997) Epidural epinephrine and clonidine: segmental analgesia and effects on different pain modalities. Anesthesiology 87:785-794

Curatolo M, Petersen-Felix S, Arendt-Nielsen L (2000) Sensory assessment of regional analgesia in humans: a review of methods and applications. Anesthesiology 93:1517-1530

Daenen L, Nijs J, Cras P, Wouters K et al (2014) Changes in pain modulation occur soon after whiplash trauma but are not related to altered perception of distorted visual feedback. Pain Pract 14:588-598

Demedts I, Tack J (1998) Chest pain of esophageal origin. Curr Opin Gastroenterol 14:340-344

Doll RJ, Buitenweg JR, Meijer HG, Veltink PH (2014) Tracking of nociceptive thresholds using adaptive psychophysical methods. Behav Res Methods 46:55-66

Doll RJ, van Amerongen G, Hay JL, Groeneveld GJ et al (2016) Responsiveness of electrical nociceptive detection thresholds to capsaicin (8\%)-induced changes in nociceptive processing. Exp Brain Res 234:2505-2514

Dotson RM (1997) Clinical neurophysiology laboratory tests to assess the nociceptive system in humans. J Clin Neurophysiol 14:32-45

Drewes AM, Schipper KP, Dimcevski G, Petersen P et al (2002) Multimodal assessment of pain in the esophagus: a new experimental model. Am J Physiol Gastrointest Liver Physiol 283:95-103

Drewes AM, Schipper KP, Dimcevski G, Petersen P et al (2003a) Gut pain and hyperalgesia induced by capsaicin: a human experimental model. Pain 104:333-341

Drewes AM, Schipper KP, Dimcevski G, Petersen P et al (2003b) Multi-modal induction and assessment of allodynia and hyperalgesia in the human oesophagus. Eur J Pain 7:539-549

Drewes AM, Reddy H, Staahl C, Pedersen J et al (2005) Sensory-motor responses to mechanical stimulation of the esophagus after sensitization with acid. World $\mathbf{J}$ Gastroenterol 11:4367-4374

Dworkin RH, O'Connor AB, Audette J, Baron R et al (2010) Recommendations for the pharmacological management of neuropathic pain: an overview and literature update. Mayo Clin Proc 85:3-14

Dyck PJ, Peroutka S, Rask C, Burton E et al (1997) Intradermal recombinant human nerve growth factor induces pressure allodynia and lowered heat-pain threshold in humans. Neurology 48:501-505

Eckhardt K, Li S, Ammon S, Schanzle G et al (1998) Same incidence of adverse drug events after codeine administration irrespective of the genetically determined differences in morphine formation. Pain 76:27-33

Enggaard TP, Poulsen L, Arendt-Nielsen L, Hansen SH et al (2001) The analgesic effect of codeine as compared to imipramine in different human experimental pain models. Pain 92:277-282

Finnerup NB, Sindrup SH, Jensen TS (2010) The evidence for pharmacological treatment of neuropathic pain. Pain 150:573-581

Finnerup NB, Attal N, Haroutounian S, Kamerman P et al (2015) Pharmacotherapy for neuropathic pain in adults: a systematic review and meta-analysis. Lancet Neurol 14:162-173

Fitzpatrick TB (1988) The validity and practicality of sunreactive skin types I through VI. Arch Dermatol 124:869-871

Frølund F, Frølund C (1986) Pain in general practice: pain as a cause of patient-doctor contact. Scand J Prim Health Care 4:97-100

Fruhstorfer H, Gross W, Selbmann O (2001) Von Frey hairs: new materials for a new design. Eur $\mathrm{J}$ Pain 5:341-342

Fujii K, Motohashi K, Umino M (2006) Heterotopic ischemic pain attenuates somatosensory evoked potentials induced by electrical tooth stimulation: diffuse noxious inhibitory controls in the trigeminal nerve territory. Eur J Pain 10:495-504 
Ge HY, Madeleine P, Cairns BE, Arendt-Nielsen L (2006) Hypoalgesia in the referred pain areas after bilateral injections of hypertonic saline into the trapezius muscles of men and women: a potential experimental model of gender-specific differences. Clin J Pain 22:37-44

Goubert D, Danneels L, Cagnie B, van Oosterwijck J et al (2015) Effect of pain induction or pain reduction on conditioned pain modulation in adults: a systematic review. Pain Pract 8:765-777

Gracely RH (1994) Studies of pain in normal man. In: Wall PD, Melzack R (eds) Textbook of pain, 3rd edn. Churchill Livingstone, Edinburgh, pp 315-336

Gracely RH (2013) Studies of pain in human subjects. In: McMahon SB, Koltzenburg M, Tracey I, Turk DC (eds) Wall and Melzack's textbook of pain, 6th edn. Elsevier, Philidelphia, pp 283-300

Granot M, Granovsky Y, Sprecher E, Nir RR, Yarnitsky D (2006) Contact heat-evoked temporal summation: tonic versus repetitive-phasic stimulation. Pain 122:295-305

Graven-Nielsen T, Mense S (2001) The peripheral apparatus of muscle pain: evidence from animal and human studies. Clin J Pain 17:2-10

Graven-Nielsen T, Arendt-Nielsen L, Svensson P, Staehelln Jensen T (1997) Quantification of local and referred muscle pain in humans after sequential i.m. injections of hypertonic saline. Pain 69:111-117

Graven-Nielsen T, Babenko V, Svensson P, Arendt-Nielsen L (1998) Experimentally induced muscle pain induces hypoalgesia in heterotopic deep tissues, but not in homotopic deep tissues. Brain Res 787:203-210

Graven-Nielsen T, Arendt-Nielsen L, Mense S (2002) Thermosensitivity of muscle: high-intensity thermal stimulation of muscle tissue induces muscle pain in humans. J Physiol 540:647-656

Grech R, Cassar T, Muscat J, Camilleri KP et al (2008) Review on solving the inverse problem in EEG source analysis. J Neuroeng Rehabil 5:25

Gustorff B, Anzenhofer S, Sycha T, Lehr S et al (2004) The sunburn pain model: the stability of primary and secondary hyperalgesia over 10 hours in a crossover setting. Anesth Analg 98:173-177

Hagenouw RR, Bridenbaugh PO, van Egmond J, Stuebing R (1986) Tourniquet pain: a volunteer study. Anesth Analg 65:1175-1180

Hampson JP, Reed BD, Clauw DJ, Bhavsar R et al (2013) Augmented central pain processing in vulvodynia. $\mathrm{J}$ Pain 14:579-589

Handwerker HO, Kobal G (1993) Psychophysiology of experimentally induced pain. Physiol Rev 73:639-671

Hardy JD, Wolff HG, Goodell H (1940) Studies on pain. A new method for measuring pain threshold: observations on spatial summation of pain. J Clin Invest 19:649-657

Hatem S, Attal N, Willer JC, Bouhassira D (2006) Psychophysical study of the effects of topical application of menthol in healthy volunteers. Pain 122:190-196

Hauck M, Domnick C, Lorenz J, Gerloff C et al (2015) Top-down and bottom-up modulation of pain-induced oscillations. Front Hum Neurosci 9:375
Hay JL, Okkerse P, van Amerongen G, Groeneveld GJ (2016) Determining pain detection and tolerance thresholds using an integrated, multi-modal pain task battery. J Vis Exp 14:110

Heinricher MM, Fields L (2013) Central nervous system mechanisms of pain modulation. In: McMahon SB, Koltzenburg M, Tracey I, Turk DC (eds) Wall and Melzack's textbook of pain, 6th edn. Elsevier, Philidelphia, pp 129-142

Hernández N, Dmitrieva N, Vanegas H (1994) Medullary on-cell activity during tail-flick inhibition produced by heterotopic noxious stimulation. Pain 58:393-401

Hertel HC, Howaldt B, Mense S (1976) Responses of group IV and group III muscle afferents to thermal stimuli. Brain Res 113:201-205

Hu L, Zhang ZG, Mouraux A, Iannetti GD (2015) Multiple linear regression to estimate time-frequency electrophysiological responses in single trials. NeuroImage 111:442-453

Huettel SA, Song AW, McCarthy G (eds) (2014) Functional magnetic resonance ingaging, 2nd edn. Sinauer Associates Inc, Sunderland

Hüllemann P, Watfeh R, Shao YQ, Nerdal A (2015) Peripheral sensitization reduces laser-evoked potential habituation. Neurophysiol Clin 45:457-467

Ikeda H, Heinke B, Ruscheweyh R, Sandkühler J (2003) Synaptic plasticity in spinal lamina I projection neurons that mediate hyperalgesia. Science 299:1237-1240

Ilkjaer S, Petersen KL, Brennum J, Wernberg $M$ et al (1996) Effect of systemic N-methyl-D-aspartate receptor antagonist (ketamine) on primary and secondary hyperalgesia in humans. Br J Anaesth 76:829-834

Ing Lorenzini K, Besson M, Daali Y, Salomon D et al (2012) Validation of the simplified UVB model to assess the pharmacodynamics of analgesics in healthy human volunteers. Chimia (Aarau) 66:296-299

Ingvar M (1999) Pain and functional imaging. Philos Trans R Soc Lond Ser B Biol Sci 354:1347-1358

Inui K, Kakigi R (2012) Pain perception in humans: use of intraepidermal electrical stimulation: figure 1. J Neurol Neurosurg Psychiatry 83:551-556

Jobert M, Wilson FJ, Roth T, Ruigt GSF (2013) Guidelines for the recording and evaluation of pharmaco-sleep studies in man: the international pharmaco-EEG society (IPEG). Neuropsychobiology 67:127-167

Johnson AC, Greenwood-Van Meerveld B (2016) The pharmacology of visceral pain. Adv Pharmacol 75:273-301

Jones SF, McQuay HJ, Moore RA, Hand CW (1988) Morphine and ibuprofen compared using the cold pressor test. Pain 34:117-122

Kakigi R (1994) Diffuse noxious inhibitory control. Reappraisal by pain-related somatosensory evoked potentials following $\mathrm{CO} 2$ laser stimulation. J Neurol Sci 125:198-205

Kakigi R, Inui K, Tamura Y (2005) Electrophysiological studies on human pain perception. Clin Neurophysiol 116:743-763 
Kern D, Plantevin F, Bouhassira D (2008) Effects of morphine on the experimental illusion of pain produced by a thermal grill. Pain 139:653-659

Kidd BL, Urban LA (2001) Mechanisms of inflammatory pain. Br J Anaesth 87:3-11

Kilo S, Schmelz M, Koltzenburg M, Handwerker HO (1994) Different patterns of hyperalgesia induced by experimental inflammation in human skin. Brain 117:385-396

Kissin I (2010) The development of new analgesics over the past 50 years: a lack of real breakthrough drugs. Anesth Analg 110:780-789

Klein T, Magerl W, Hopf HC, Sandkühler J (2004) Perceptual correlates of nociceptive long-term potentiation and long-term depression in humans. J Neurosci 24:964-971

Klein T, Stahn S, Magerl W, Treede RD (2008) The role of heterosynaptic facilitation in long-term potentiation (LTP) of human pain sensation. Pain 139:507-519

Kocyigit F, Akalin E, Gezer NS, Orbay O et al (2012) Functional magnetic resonance imaging of the effects of low-frequency transcutaneous electrical nerve stimulation on central pain modulation. A double-blind, placebo-controlled trial. Clin J Pain 28:581-588

Koltzenburg M, Lundberg LE, Torebjörk HE (1992) Dynamic and static components of mechanical hyperalgesia in human hairy skin. Pain 51:207-219

Koppert W, Dern SK, Sittl R, Albrecht S et al (2001) A new model of electrically evoked pain and hyperalgesia in human skin: the effects of intravenous alfentanil, $\mathrm{S}(+)$ ketamine, and lidocaine. Anesthesiology 95:395-402

Korotkov A, Ljubisavljevic M, Thunberg J, Kataeva G et al (2002) Changes in human regional cerebral blood flow following hypertonic saline induced experimental muscle pain: a positron emission tomography study. Neurosci Lett 335:119-123

Krarup AL, Gunnarsson J, Brun J, Poulakis A et al (2013) Exploration of the effects of gender and mild esophagitis on esophageal pain thresholds in the normal and sensitized state of asymptomatic young volunteers. Neurogastroenterol Motil 25:766-e580

Kumar K, Railton C, Tawfic Q (2016) Tourniquet application during anesthesia: "what we need to know?". J Anaesthesiol Clin Pharmacol 32:424-430

van Laarhoven AI, Kraaimaat FW, Wilder-Smith OH, van Riel PL, van de Kerkhof PC, Evers AW (2013) Sensitivity to itch and pain in patients with psoriasis and rheumatoid arthritis. Exp Dermatol 22:530-534

Laird JM, Bennett GJ (1993) An electrophysiological study of dorsal horn neurons in the spinal cord of rats with an experimental peripheral neuropathy. J Neurophysiol 69:2072-2085

Lapotka M, Ruz M, Salamanca Ballesteros A, Ocon Hernandez O (2017) Cold pressor gel test: a safe alternative to the cold pressor test in fMRI. Magn Reson Med 78:1464-1468

Latremoliere A, Woolf CJ (2009) Central sensitization: a generator of pain hypersensitivity by central neural plasticity. J Pain 10:895-926
Laursen RJ, Graven-Nielsen T, Jensen TS, Arendt-Nielsen L (1997) Referred pain is dependent on sensory input from the periphery: a psychophysical study. Eur J Pain 1:261-269

Lautenbacher S, Roscher S, Strian F (2002) Inhibitory effects do not depend on the subjective experience of pain during heterotopic noxious conditioning stimulation (HNCS): a contribution to the psychophysics of pain inhibition. Eur J Pain 6:365-374

Le Bars D, Dickenson AH, Besson JM (1979) Diffuse noxious inhibitory controls (DNIC). I. Effects on dorsal horn convergent neurones in the rat. Pain 6:283-304

Lee YS, Kho HS, Kim YK, Chung SC (2007) Influence of topical capsaicin on facial sensitivity in response to experimental pain. J Oral Rehabil 34:9-14

Li H (2017) TRP channel classification. Adv Exp Med Biol 976:1-8

Lötsch J, Angst MS (2003) The $\mu$-opioid agonist remifentanil attenuates hyperalgesia evoked by blunt and punctuated stimuli with different potency: a pharmacological evaluation of the freeze lesion in humans. Pain 102:151-161

Lötsch J, Oertel BG, Ultsch A (2014) Human models of pain for the prediction of clinical analgesia. Pain 155:2014-2021

Louvel D, Delvaux M, Staumont G, Camman F et al (1996) Intracolonic injection of glycerol: a model for abdominal pain in irritable bowel syndrome? Gastroenterology 110:351-361

Macfarlane GJ, McBetch J, Jones GT (2013) Epidemiology of pain. In: McMahon SB, Koltzenburg M, Tracey I, Turk DC (eds) Wall and Melzack's textbook of pain, 6th edn. Elsevier, Philidelphia, pp 232-247

Maggi CA (1990) The dual function of capsaicin-sensitive sensory nerves in the bladder and urethra. Ciba Found Symp 151:77-90

Mauderli AP, Vierck CJ Jr, Cannon RL, Rodrigues A et al (2003) Relationships between skin temperature and temporal summation of heat and cold pain. $\mathbf{J}$ Neurophysiol 90:100-109

McQuay HJ, Moore A (2013) Methods of therapeutic trials. In: McMahon SB, Koltzenburg M, Tracey I, Turk DC (eds) Wall and Melzack's textbook of pain, 6th edn. Elsevier, Philidelphia, pp 402-412

Melzack R (1975) The McGill pain questionnaire: major properties and scoring methods. Pain 1:277-299

Melzack R (2005) The McGill pain questionnaire: from description to measurement. Anesthesiology 103:199-202

Melzack R, Katz J (2013) Pain measurement in adult patients. In: McMahon SB, Koltzenburg M, Tracey I, Turk DC (eds) Wall and Melzack's textbook of pain, 6th edn. Elsevier, Philidelphia, pp 301-314

Messeguer A, Plannells-Cases P, Ferrer-Montiel A (2006) Physiology and pharmacology of the vanilloid receptor. Curr Neuropharmacol 4:1-15

Meyer RA, Treede RD (2004) Mechanisms of secondary hyperalgesia: a role for myelinated nociceptors in punctate hyperalgesia. In: Brune K, Handwerker HO (eds) 
Hyperalgesia: molecular mechanisms and clinical implications, 1st edn. IASP Press, Seatlle, pp 143-155

Mikkelsen S, Ilkjaer S, Brennum J, Borgbjerg FM et al (1999) The effect of naloxone on ketamine-induced effects on hyperalgesia and ketamine-induced side effects in humans. Anesthesiology 90:1539-1545

Mitchell LA, MacDonald RA, Brodie EE (2004) Temperature and the cold pressor test. J Pain 5:233-237

Möller KA, Johansson B, Berge OG (1998) Assessing mechanical allodynia in the rat paw with a new electronic algometer. J Neurosci Methods 84:41-47

Moore DJ, Keogh E, Crombez G, Eccleston C (2013) Methods for studying naturally occurring human pain and their analogues. Pain 154:190-199

Moore RA, Wiffen PJ, Derry S, Maguire T (2015) Nonprescription (OTC) oral analgesics for acute pain - an overview of Cochrane reviews. Cochrane Database Syst Rev 11:CD010794

Morton DL, Sandhu JS, Jones AK (2016) Brain imaging of pain: state of the art. J Pain Res 9:613-624

Mouraux A, Iannetti GD (2008) Across-trial averaging of event-related EEG responses and beyond. Magn Reson Imaging 26:1041-1054

Mouraux A, Guérit JM, Plaghki L (2003) Non-phase locked electroencephalogram (EEG) responses to $\mathrm{CO} 2$ laser skin stimulations may reflect central interactions between a partial differential- and C-fibre afferent volleys. Clin Neurophysiol 114:710-722

Mouraux A, Iannetti GD, Plaghki L (2010) Low intensity intra-epidermal electrical stimulation can activate Aסnociceptors selectively. Pain 150:199-207

Ness TJ, Gebhart GF (1990) Visceral pain: a review of experimental studies. Pain 41:167-234

Nie H, Arendt-Nielsen L, Madeleine P, Graven-Nielsen T (2006) Enhanced temporal summation of pressure pain in the trapezius muscle after delayed onset muscle soreness. Exp Brain Res 170:182-190

Niesters M, Dahan A, Swartjes M, Noppers I et al (2011) Effect of ketamine on endogenous pain modulation in healthy volunteers. Pain 152:656-663

Nir RR, Yarnitsky D (2015) Conditioned pain modulation. Curr Opin Support Palliat Care 9:131-137

Ochoa J, Mair WG (1969) The normal sural nerve in man. I. Ultrastructure and numbers of fibres and cells. Acta Neuropathol 13:197-216

Oertel BG, Lötsch J (2013) Clinical pharmacology of analgesics assessed with human experimental pain models: bridging basic and clinical research. $\mathrm{Br} \mathrm{J}$ Pharmacol 168:534-553

Ogawa S, Lee TM, Kay AR, Tank DW (1990) Brain magnetic resonance imaging with contrast dependent on blood oxygenation. Proc Natl Acad Sci U S A 87:9868-9872

Okkerse P, van Amerongen G, de Kam ML, Stevens J et al (2017) The use of a battery of pain models to detect analgesic properties of compounds: a two-part fourway crossover study. Br J Clin Pharmacol 83:976-990

Olesen AE, Staahl C, Arendt-Nielsen L, Drewes AM (2010) Different effects of morphine and oxycodone in experimentally evoked hyperalgesia: a human translational study. Br J Clin Pharmacol 70:189-200

Olesen AE, Andresen T, Staahl C, Drewes AM (2012) Human experimental pain models for assessing the therapeutic efficacy of analgesic drugs. Pharmacol Rev 64:722-779

Olesen AE, Brock C, Sverrisdóttir E, Larsen IM et al (2014) Sensitivity of quantitative sensory models to morphine analgesia in humans. J Pain Res 7:717-726

Olofsen E, Romberg R, Bijl H, Mooren R et al (2005) Alfentanil and placebo analgesia: no sex differences detected in models of experimental pain. Anesthesiology 103:130-139

Page GD, France CR (1997) Objective evidence of decreased pain perception in normotensives at risk for hypertension. Pain 73:173-180

Pedersen JL, Kehlet H (1998) Hyperalgesia in a human model of acute inflammatory pain: a methodological study. Pain 74:139-151

Petty BG, Cornblath DR, Adornato BT, Chaudhry V et al (1994) The effect of systemically administered recombinant human nerve growth factor in healthy human subjects. Ann Neurol 36:244-224

Peyron R, Laurent B, García-Larrea L (2000) Functional imaging of brain responses to pain. A review and metaanalysis (2000). Neurophysiol Clin 30:263-288

Pfau DB, Klein T, Putzer D, Pogatzki-Zahn EM et al (2011) Analysis of hyperalgesia time courses in humans after painful electrical high-frequency stimulation identifies a possible transition from early to late LTP-like pain plasticity. Pain 152:1532-1539

Plaghki L, Mouraux A (2003) How do we selectively activate skin nociceptors with a high power infrared laser? Physiology and biophysics of laser stimulation. Neurophysiol Clin 33:269-277

Polianskis R, Graven-Nielsen T, Arendt-Nielsen L (2001) Computer-controlled pneumatic pressure algometry-a new technique for quantitative sensory testing. Eur $\mathbf{J}$ Pain 5:267-277

Popescu A, LeResche L, Truelove EL, Drangsholt MT (2010) Gender differences in pain modulation by diffuse noxious inhibitory controls: a systematic review. Pain 150:309-318

Porro CA (2003) Functional imaging and pain: behavior, perception, and modulation. Neuroscientist 9:354-369

Price DD (1996) Selective activation of A-delta and C nociceptive afferents by different parameters of nociceptive heat stimulation: a tool for analysis of central mechanisms of pain. Pain 68:1-3

Price DD (2000) Psychological and neural mechanisms of the affective dimension of pain. Science 288:1769-1772

Pud D, Granovsky Y, Yarnitsky D (2009) The methodology of experimentally induced diffuse noxious inhibitory control (DNIC)-like effect in humans. Pain 144:16-19

Rainville P (2002) Brain mechanisms of pain affect and pain modulation. Curr Opin Neurobiol 12:195-204 
Reddy H, Arendt-Nielsen L, Staahl C, Pedersen J et al (2005) Gender differences in pain and biomechanical responses after acid sensitization of the human esophagus. Dig Dis Sci 50:2050-2058

Roberts K, Papadaki A, Goncalves C, Tighe M et al (2008) Contact heat evoked potentials using simultaneous Eeg and Fmri and their correlation with evoked pain. BMC Anesthesiol 8:8

Roberts K, Shenoy R, Anand P (2011) A novel human volunteer pain model using contact heat evoked potentials (CHEP) following topical skin application of transient receptor potential agonists capsaicin, menthol and cinnamaldehyde. J Clin Neurosci 18:926-932

Rosendal L, Larsson B, Kristiansen J, Peolsson M (2004) Increase in muscle nociceptive substances and anaerobic metabolism in patients with trapezius myalgia: microdialysis in rest and during exercise. Pain 112:324-334

Rukwied R, Mayer A, Kluschina O, Obreja O (2010) NGF induces non-inflammatory localized and lasting mechanical and thermal hypersensitivity in human skin. Pain 148:407-413

Ruscheweyh R, Weinges F, Schiffer M, Bäumler M (2015) Control over spinal nociception as quantified by the nociceptive flexor reflex (RIII reflex) can be achieved under feedback of the RIII reflex. Eur $\mathrm{J}$ Pain 19:480-489

Sandkühler J (2009) Models and mechanisms of hyperalgesia and allodynia. Physiol Rev 89:707-758

Sandrini G, Alfonsi E, Ruiz L, Livieri C et al (1989) Agerelated changes in excitability of nociceptive flexion reflex. An electrophysiological study in school-age children and young adults. Funct Neurol 4:53-58

Sayre RM, Desrochers DL, Wilson CJ, Marlowe E (1981) Skin type, minimal erythema dose (MED), and sunlight acclimatization. J Am Acad Dermatol 5:439-443

Schaffler K, Nicolas LB, Borta A, Brand T et al (2017) Investigation of the predictive validity of laser-EPs in normal, UVB-inflamed and capsaicin-irritated skin with four analgesic compounds in healthy volunteers. Br J Clin Pharmacol 83:1424-1435

Schouenborg J, Weng HR, Kalliomäki J, Holmberg H (1995) A survey of spinal dorsal horn neurones encoding the spatial organization of withdrawal reflexes in the rat. Exp Brain Res 106:19-27

Schulte H, Segerdahl M, Graven-Nielsen T, Grass S (2006) Reduction of human experimental muscle pain by alfentanil and morphine. Eur J Pain 10:733-741

Sengupta J, Gebhart G (1994) Gastrointestinal afferent fibers and sensation. In: Johnson LR (ed.) Physiology of the Gastrointestinal Tract, 3rd edn. Raven, New York, pp 483-519

Serra J, Campero M, Ochoa J (1998) Flare and hyperalgesia after intradermal capsaicin injection in human skin. J Neurophysiol 80:2801-2810

Shukla S, Torossain A, Duann JR, Keung A (2011) The analgesic effect of electroacupunture on acute thermal pain perception - a central neural correlate study with fMRI. Mol Pain 7:45-56
Simone DA, Ngeow JYF, Putterman GJ, LaMotte RH (1987) Hyperalgesia to heat after intradermal injection of capsaicin. Brain Res 418:201-203

Skljarevski V, Ramadan NM (2002) The nociceptive flexion reflex in humans - review article. Pain 96:3-8

Smith GM, Egbert LD, Markowitz RA, Mosteller F (1966) A VAS is used to assess the subject's pain intensity. J Pharmacol Exp Ther 154:324-332

Song J, Davey C, Poulsen C, Luu P et al (2015) EEG source localization: sensor density and head surface coverage. J Neurosci Methods 256:9-12

Staahl C, Drewes AM (2004) Experimental human pain models: a review of standardised methods for preclinical testing of analgesics. Basic Clin Pharmacol Toxico 195:97-111

Staahl C, Christrup LL, Andersen SD, Arendt-Nielsen L et al (2006) A comparative study of oxycodone and morphine in a multi-modal, tissue-differentiated experimental pain model. Pain 123:28-36

Staahl C, Olesen AE, Andresen T, Arendt-Nielsen L et al (2009a) Assessing analgesic actions of opioids by experimental pain models in healthy volunteers - an updated review. Br J Clin Pharmacol 68:149-168

Staahl C, Olesen AE, Andresen T, Arendt-Nielsen L et al (2009b) Assessing efficacy of non-opioid analgesics in experimental pain models in healthy volunteers: an updated review. Br J Clin Pharmacol 68:322-341

Svendsen O, Edwards CN, Lauritzen B, Rasmussen AD (2005) Intramuscular injection of hypertonic saline: in vitro and in vivo muscle tissue toxicity and spinal neurone c-fos expression. Basic Clin Pharmacol Toxicol 97:52-57

Svenson P, Arendt-Nielsen L (1995) Induction and assessment of experimental muscle pain. J Electromyogr Kinesiol 5:131-140

Svensson P, Cairns BE, Wang K, Arendt-Nielsen L (2003) Injection of nerve growth factor into human masseter muscle evokes long-lasting mechanical allodynia and hyperalgesia. Pain 104:241-247

Svensson P, Wang K, Arendt-Nielsen L, Cairns BE (2008) Effects of NGF-induced muscle sensitization on proprioception and nociception. Exp Brain Res 189:1-10

Thalhammer JG, LaMotte RH (1982) Spatial properties of nociceptor sensitization following heat injury of the skin. Brain Res 231:257-265

Torebjörk HE, Lundberg LE, LaMotte RH (1992) Central changes in processing of mechanoreceptive input in capsaicin-induced secondary hyperalgesia in humans. J Physiol 448:765-780

Tracey I, Mantyh PW (2007) The cerebral signature for pain perception and its modulation. Neuron 55:377-391

Treede RD, Lorenz J, Baumgärtner U (2003) Clinical usefulness of laser-evoked potentials. Neurophysiol Clin 33:303-314

Tuveson B, Leffler AS, Hansson P (2006) Time dependent differences in pain sensitivity during unilateral ischemic pain provocation in healthy volunteers. Eur J Pain $10: 225-232$ 
Vo L, Hood S, Drummond PD (2016) Involvement of opioid receptors and $\alpha 2$-adrenoceptors in inhibitory pain modulation processes: a double-blind placebocontrolled crossover study. J Pain 17:1164-1173

Wager TD, Atlas LY, Lindquist MA, Roy M et al (2013) An fMRI-based neurologic signature of physical pain. N Engl J Med 368:1388-1397

Willer JC (1977) Comparative study of perceived pain and nociceptive flexion reflex in man. Pain 3:69-80

Woolf CJ (1983) Evidence for a central component of postinjury pain hypersensitivity. Nature 306:686-688

Woolf CJ (2011) Central sensitization: implications for the diagnosis and treatment of pain. Pain 152:S2-15
Woolf CJ, Max MB (2001) Mechanism-based pain diagnosis: issues for analgesic drug development. Anesthesiology 95:241-249

Yang H, Meijer HGE, Doll RJ, Buitenweg JR (2015) Computational modeling of Adelta-fiber-mediated nociceptive detection of electrocutaneous stimulation. Biol Cybern 109:479-491

Yarnitsky D, Arendt-Nielsen L, Bouhassira D, Edwards RR et al (2010) Recommendations on terminology and practice of psychophysical DNIC testing. Eur J Pain 14:339 